\title{
RECORDS OF WELLS, DRILLERS' LOGS, WATER-LEVEL MEASUREMENTS, AND CHEMICAL ANALYSES OF GROUND WATER IN CHAMBERS, LIBERTY, AND MONTGOMERY COUNTIES, TEXAS, 1985-89
}

By Glenn L. Locke

U.S. GEOLOGICAL SURVEY

Open-File Report 90-594

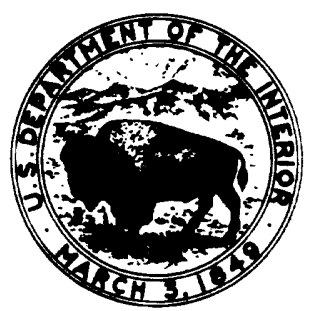

Prepared in cooperation with the CITY OF HOUSTON and the HARRIS-GALVESTON COASTAL SUBSIDENCE DISTRICT 


\section{U.S. DEPARTMENT OF THE INTERIOR}

MANUEL LUJAN, JR., Secretary

\section{U.S. GEOLOGICAL SURVEY}

Dallas L. Pock, Director

For additional information write to:

District Chief

U.S. Geological Survey

8011 Cameron Rd., Bldg. 1

Austin, TX 78753
Copies of this report can be purchased from:

U.S. Geological Survey Books and Open-File Reports Section Federal Center Box 25425

Denver, CO 80225 
Abstract 1

Introduction

Well-numbering system

Selected references

2

2

\section{ILLUSTRATIONS}

[Plates in pocket]

Plates 1-3. Maps showing location of wells in:

1. Chambers County

2. Liberty County

3. Montgomery County

Figure 1. Map showing location of Chambers, Liberty, and Montgomery Counties

\section{TABLES}

Table 1. Records of wells in Chambers County

5

2. Drillers' logs of wells in Chambers County

3. Water levels in wells in Chambers County

4. Chemical analyses of water from a well in Chambers County

5. Records of wells in Liberty County

6. Drillers' logs of wells in Liberty County

7. Water levels in wells in Liberty County

8. Chemical analyses of water from wells in Liberty County

9. Records of wells in Montgomery County --
10. Drillers' logs of wells in Montgomery County

11. Water levels in wells in Montgomery County

12. Chemical analyses of water from wells in Montgomery County 
CONVERSION FACTORS

\begin{tabular}{lll}
\hline Multiply & By & To obtain \\
\hline & & \\
inch & 25.4 & millimeter \\
foot & 0.3048 & meter \\
gallon per minute & 0.06308 & liter per second \\
& 0.003785 & cubic meter per minute \\
\hline
\end{tabular}

Sea level: In this report "sea level" refers to the National Geodetic Vertical Datum of 1929 (NGVD of 1929)--a geodetic datum derived from a general adjustment of the first-order level nets of the United States and Canada, formerly called Sea Level Datum of 1929. 
RECORDS OF WELLS, DRILLERS' LOGS, WATER-LEVEL MEASUREMENTS,

AND CHEMICAL ANALYSES OF GROUND WATER IN CHAMBERS,

LIBERTY, AND MONTGOMERY COUNTIES, TEXAS, 1985-89

\author{
By Glenn L. Locke
}

\title{
ABSTRACT
}

Data for water wells and ground water in Chambers, Liberty, and Montgomery Counties were collected during 1985-89 by the U.S. Geological Survey. This report presents a compilation of records for 4 wells in Chambers County, 8 wells in Liberty County, and 64 wells in Montgomery County. Drillers' logs of 60 wells, water levels for 84 wells, chemical analyses of water for 11 wells, and water levels and chemical analyses of water from previously inventoried wells also are presented in this report. 


\section{INTRODUCTION}

Hydrologic data from Chambers, Liberty, and Montgomery Counties (fig. 1) are collected by the U.S. Geological Survey in cooperation with the City of Houston and the Harris-Galveston Coastal Subsidence District to help monitor the development of the ground-water resources of the Houston-Galveston region. The data-collection program consists of conducting inventories of wells, measuring water levels in observation wells, and analyzing water from selected wells to describe the chemical quality of the ground water. Data collected are published at 5-year intervals.

Records of wells, drillers' logs of wells, water-level measurements, and chemical analyses of water for 1985-89 are given in tables 1-12 at the end of this report. The water-level measurements and chemical analyses are from the newly inventoried wells or from wells previously inventoried. Descriptions of the geology and hydrology of the area and hydrologic data collected before 1985 were published in reports listed in the "Selected References" section of this report. The location of wells listed is shown on plates 1-3.

Data for 76 mostly large-diameter (greater than 4 inches) newly inventoried wells--4 wells in Chambers County (table 1), 8 wells in Liberty County (table 5), and 64 wells in Montgomery County (table 9)--were collected during 1985-89. Some wells that were less than 5 inches in diameter were inventoried to obtain additional water-level or water-quality data. Drillers' logs of 60 wells in the inventory (tables 2, 6, and 10) are included in the tabulations.

Water-level measurements were made in 84 wells--20 wells in Chambers County (table 3), 20 wells in Liberty County (table 7), and 44 wells in Montgomery County (table 11).

Tables 4, 8, and 12 present chemical analyses of water from 11 wells. The Geological Survey sampled and analyzed the water from one well in Chambers County and one well in Montgomery County; nine of the analyses tabulated were made by commercial laboratories.

\section{WELL-NUMBERING SYSTEM}

The well-numbering system used in this report was devised by the Texas Department of Water Resources for use throughout the State. Under this system, each 1-degree quadrangle is given a number consisting of two digits. These are the first two digits in the well number. Each 1-degree quadrangle is divided into 7-1/2-minute quadrangles that are given two-digit numbers from 01 to 64 . These are the third and fourth digits of the well number. Each 7-1/2-minute quadrangle is divided into 2 1/2-minute quadrangles that are given a single-digit number from 1 to 9 . This is the fifth digit of the well number. Finally, each well within a 2-1/2-minute quadrangle is given a two-digit number in the order in which it was inventoried, starting with 01 . These are the last two digits of the well number.

On the well-location maps (pls. 1-3), only the last three digits of the well number are shown at each well location; the second two digits are shown in the northwest corner of each 7-1/2-minute quadrangle; and the first two digits are shown by large block numerals $60,61,64$, and 65 .

In addition to the seven-digit well number, a two-digit prefix is used to identify the county. The prefix for Chambers County is DH; for Liberty County, SB; and for Montgomery County, TS. 

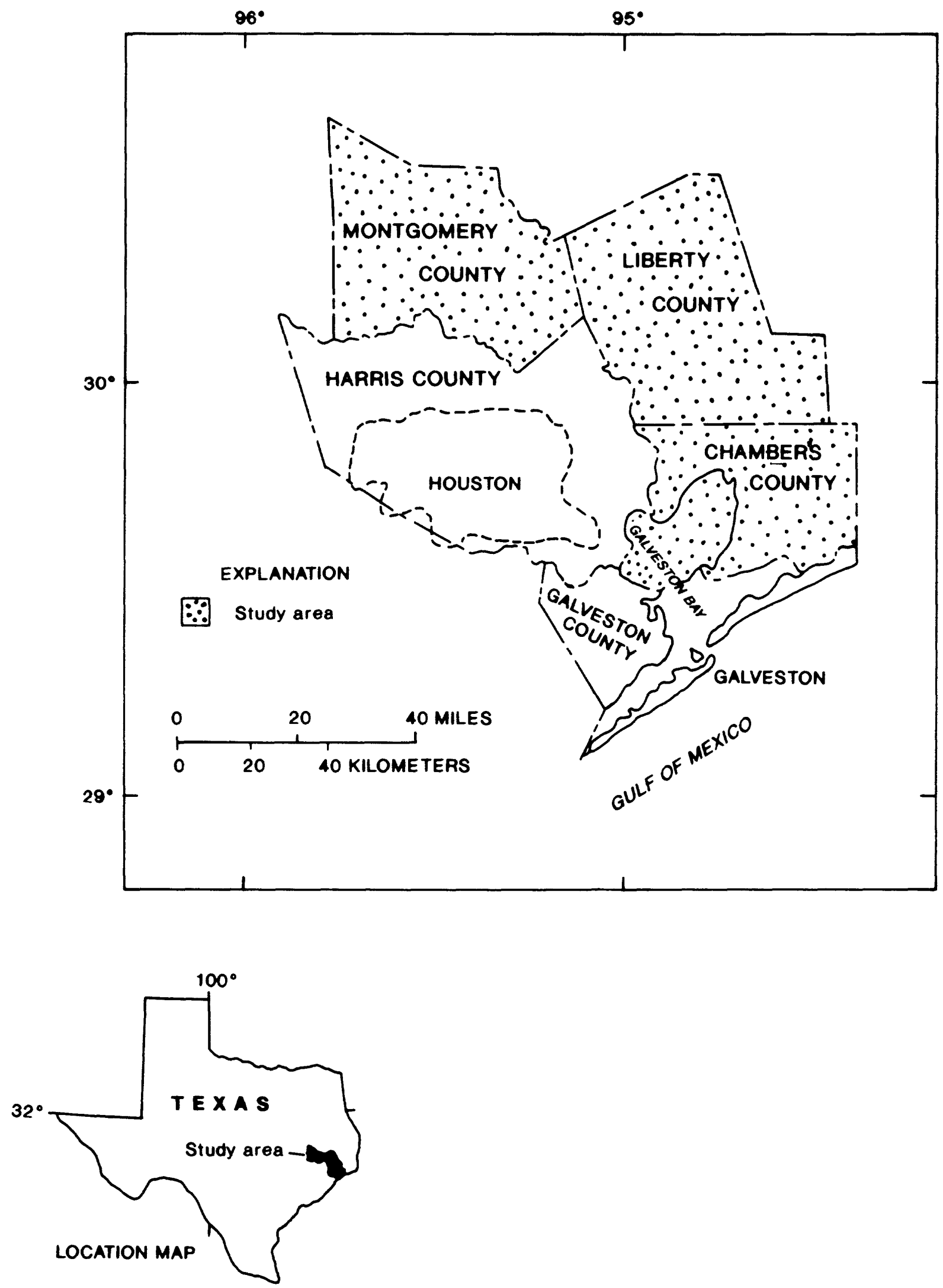

Figure 1.--Location of Chambers, Liberty, and Montgomery Counties. 


\section{SELECTED REFERENCES}

Anders, R.B., McAdoo, G.D., and Alexander, W.H., Jr., 1968, Ground-water resources of Liberty County, Texas: Texas Water Development Board Report 72, $147 \mathrm{p}$.

Naftel, W.L., Fleming, Bobbie, and Vaught, Kenneth, 1976, Records of wells, drillers' logs, water-level measurements, and chemical analyses of ground water in Chambers, Liberty, and Montgomery Counties, Texas, 1966-74: Texas Water Development Board Report 202, 62 p.

Popkin, B.P., 1971, Ground-water resources of Montgomery County, Texas: Texas Water Development Board Report 136, $149 \mathrm{p}$.

Ratzlaff, K.W., Lind, W.B., and Ranzau, C.E., Jr., 1983, Records of wells, drillers' logs, water-level measurements, and chemical analyses of ground water in Chambers, Liberty, and Montgomery Counties, Texas, 1975-79: Texas Department of Water Resources Report 280, 39 p.

Wesselman, J.B., 1971, Ground-water resources of Chambers and Jefferson Counties, Texas, with a section on Quaternary geology, by Saul Aronow: Texas Water Development Board Report 133, $182 \mathrm{p}$.

Williams, J.F. III, Coplin, L.S., Ranzau, C.E., Jr., and Lind, W.B., 1986, Records of wells, drillers' logs, water-level measurements, and chemical analyses of ground water in Chambers, Liberty, and Montgomery Counties, Texas, 1980-84: U.S. Geological Survey Open-File Report 86-57, 37 p. 


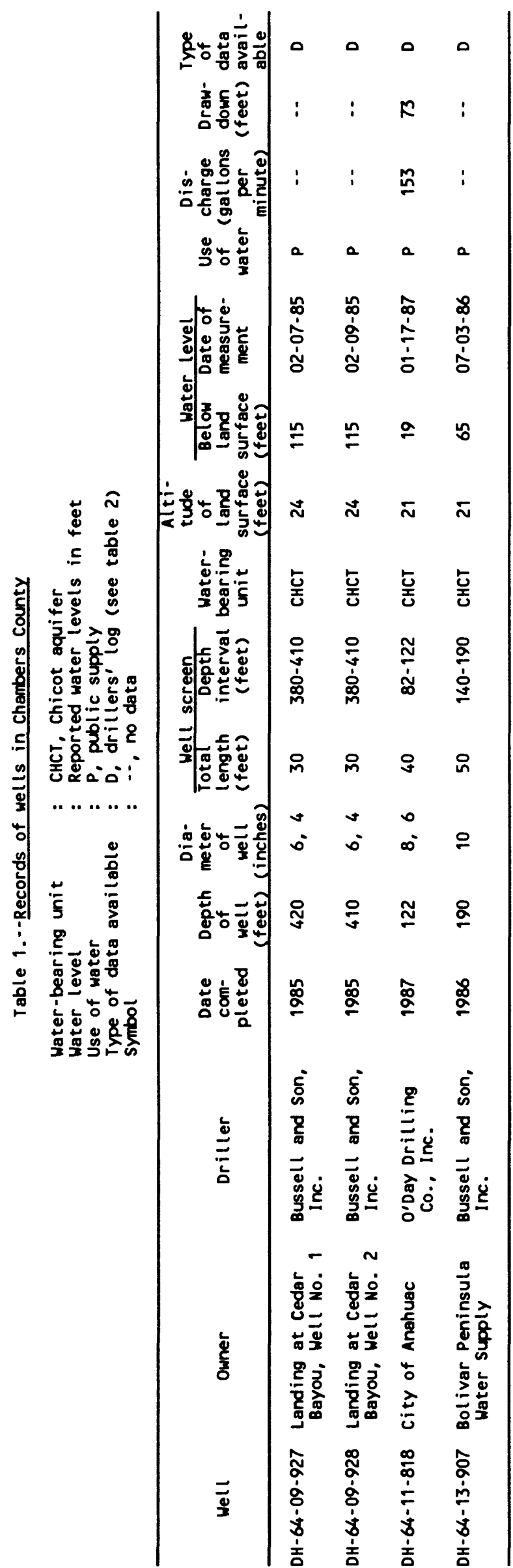


Table 2.--Drillers' logs of wells in Chambers County

Well DH-64-09-927

Owner: Landing at Cedar Bayou, Well No. 1

Driller: Bussell and Son, Inc.

\begin{tabular}{lcc}
\hline Description & $\begin{array}{c}\text { Thick- } \\
\text { ness } \\
\text { (feet) }\end{array}$ & $\begin{array}{c}\text { Depth } \\
\text { (feet) }\end{array}$ \\
\hline Clay & 35 & 35 \\
Sand & 32 & 67 \\
Clay & 254 & 321 \\
Sand & 89 & 410 \\
Clay & 10 & 420
\end{tabular}

Well DH-64-09-928

Owner: Landing at Cedar Bayou, Well No. 2

Driller: Bussell and Son, Inc.

\begin{tabular}{lcc}
\hline Description & $\begin{array}{c}\text { Thick- } \\
\text { ness } \\
\text { (feet) }\end{array}$ & $\begin{array}{c}\text { Depth } \\
\text { (feet) }\end{array}$ \\
\hline Clay & 35 & 35 \\
Sand & 32 & 67 \\
Clay & 254 & 321 \\
Sand & 89 & 410 \\
Clay & 10 & 420
\end{tabular}

Hell DH-64-11-818

Owner: City of Anahauc

Driller: O'Day Drilling Co., Inc.

\begin{tabular}{|c|c|c|}
\hline Description & $\begin{array}{l}\text { Thick- } \\
\text { ness } \\
\text { (feet) }\end{array}$ & $\begin{array}{l}\text { Depth } \\
\text { (feet) }\end{array}$ \\
\hline Topsoil & 3 & 3 \\
\hline Clay & 66 & 69 \\
\hline Sand & 55 & 124 \\
\hline \multicolumn{3}{|c|}{$\begin{array}{l}\text { Well DH-64-13-907 } \\
\text { Owner: Bol ivar Peninsula water Supply } \\
\text { Driller: Bussell and Son, Inc. }\end{array}$} \\
\hline Description & $\begin{array}{c}\text { Thick- } \\
\text { ness } \\
\text { (feet) }\end{array}$ & $\begin{array}{l}\text { Depth } \\
\text { (feet) }\end{array}$ \\
\hline $\mathrm{Clay}$ & 16 & 16 \\
\hline Sea shells & 5 & 21 \\
\hline Clay, gray & 99 & 120 \\
\hline Sand streaks & 3 & 123 \\
\hline Sand & 17 & 140 \\
\hline Sand, big & 20 & 160 \\
\hline Sand & 30 & 190 \\
\hline Sand, fine & 12 & 202 \\
\hline
\end{tabular}


Table 3. - Water levels in wells in Chambers County

Owner : H.C.I.D., Water Control and Improvement District; H.L. and P., Houston Lighting and Power Screen : Top and bottom of screened interval below land surface

Altitude : Altitude of land surface above sea level

Depth : Depth of well

Water level: Measured by the U.S. Geological Survey in feet and hundredths of feet below land surface, except as noted

Well DH-64-09-301

Owner: Chambers Co.

W.C.I.D. 1 , Well No. 5

Screen: $405-520$ feet

Altitude: 43 feet

\begin{tabular}{ll}
\hline Date & $\begin{array}{c}\text { Water } \\
\text { level }\end{array}$ \\
\hline $02-04-85$ & 110.81 \\
$10-31-85$ & 115.59 \\
$01-31-86$ & 123.20 \\
$01-07-87$ & 121.07 \\
$08-26-87$ & 119.43 \\
$01-04-89$ & 106.87
\end{tabular}

Well DH-64-09-302

Owner: Chambers Co. H.C.I.D. 1 , Hell No. 4

Screen: 418-521 feet

Altitude: 43 feet

\begin{tabular}{ll}
\hline Date & $\begin{array}{c}\text { Water } \\
\text { level }\end{array}$ \\
\hline $02-04-85$ & 108.31 \\
$10-31-85$ & 113.52 \\
$01-31-86$ & 122.04 \\
$01-07-87$ & 118.62 \\
$08-26-87$ & 117.05 \\
$01-14-88$ & 102.87
\end{tabular}

Hell DH-64-09-307

Omer: Di anond Alkali, Hell No. 3

Screen: $720-910$ feet

Altitude: 27 feet

\begin{tabular}{ll}
\hline Date & $\begin{array}{c}\text { Water } \\
\text { level }\end{array}$ \\
\hline $02-04-85$ & 106.64 \\
$11-21-85$ & 105.63 \\
$01-31-86$ & 124.32 \\
$08-28-87$ & 119.22 \\
$01-12-88$ & 143.67
\end{tabular}

Well DH-64-09-308

Owner: Di amond Alkali

Depth: 149 feet

Altitude: 27 feet

\begin{tabular}{ll}
\hline Date & $\begin{array}{c}\text { Water } \\
\text { level }\end{array}$ \\
\hline $02-04-85$ & 17.13 \\
$11-21-85$ & 17.88 \\
$01-31-86$ & 16.95 \\
$01-07-87$ & 16.00 \\
$08-28-87$ & 16.19 \\
$01-12-88$ & 16.17
\end{tabular}

Well DH-64-09-811

Owner: H.L. and P. Co. Cedar Bayou Plant, Well No. 1

Screen: 324-394 feet

Altitude: 13 feet

(Measurements reported

by owner)

\begin{tabular}{cc}
\hline Date & $\begin{array}{c}\text { Water } \\
\text { level }\end{array}$ \\
\hline $01-07-85$ & 108 \\
$01-06-86$ & 100 \\
$01-12-88$ & 96.5 \\
$12-14-88$ & 95
\end{tabular}

Well DH-64-09-921

Owner: H.L. and P. Co. Cedar Bayou Plant, Well No. 3

Screen: 335-391 feet

Alt itude: 24 feet

(Measurements reported

by owner)

\begin{tabular}{cc}
\hline Date & $\begin{array}{c}\text { Water } \\
\text { level }\end{array}$ \\
\hline $01-07-85$ & 104 \\
$01-06-86$ & 103 \\
$01-12-88$ & 101 \\
$12-14-88$ & 99
\end{tabular}

Well DH-64-09-924

Owner: H.L. and P. Co. Cedar Bayou Plant. Well No. 2

Screen: 352-400 feet

Altitude: 17 feet

(Measurements reported

by owner)

\begin{tabular}{ll}
\hline Date & $\begin{array}{l}\text { Water } \\
\text { level }\end{array}$ \\
\hline $01-07-85$ & 104.5 \\
$01-06-86$ & 103 \\
$01-12-88$ & 100.5 \\
$12-14-88$ & 99
\end{tabular}

Well DH-64-11-801

Owner: City of Anahuac, Well No. 2

Screen: 73-133 feet

Altitude: 22 feet

\begin{tabular}{ll}
\hline Date & $\begin{array}{l}\text { Water } \\
\text { level }\end{array}$ \\
\hline $11-14-85$ & 23.63 \\
$02-05-86$ & 25.52 \\
$03-20-87$ & 25.57 \\
$08-28-87$ & 24.37
\end{tabular}

Well DH-64-11-802

Owner: City of Anahuac, Well No. 1 Screen: $80-120$ feet Altitude: 22 feet

\begin{tabular}{ll}
\hline Date & $\begin{array}{l}\text { Water } \\
\text { level }\end{array}$ \\
\hline $11-14-85$ & 29 \\
$02-05-86$ & 25.48 \\
$03-20-87$ & 25.17 \\
$08-28-87$ & 24.81 \\
$01-05-89$ & 26.08
\end{tabular}

Well DH-64-11-816

Owner: City of Anahuac, Well No. 3

Screen: $80-100$ feet

Altitude: 22 feet

\begin{tabular}{cc}
\hline Date & $\begin{array}{c}\text { Water } \\
\text { level }\end{array}$ \\
\hline $11-14-85$ & 27.43 \\
$02-05-86$ & 29.75 \\
$03-20-87$ & 28.81 \\
$08-28-87$ & 25.74 \\
$01-14-88$ & 25.51 \\
$01-05-89$ & 27.90
\end{tabular}

Well DH-64-11-901

Owner: Barringer Screen: $340-350$ feet Altitude: 22 feet

\begin{tabular}{ll}
\hline Date & $\begin{array}{l}\text { Water } \\
\text { level }\end{array}$ \\
\hline $11-14-85$ & 33.80 \\
$02-05-86$ & 32.62 \\
$03-20-87$ & 32.45 \\
$09-15-87$ & 32.10 \\
$01-14-88$ & 32.52 \\
$01-05-89$ & 32.74
\end{tabular}

Well DH-64-13-306

Owner: Trinity Bay Conservation Dist. Well No. 3 Screen: 130-199 feet

Alt itude: 27 feet

\begin{tabular}{ll}
\hline Date & $\begin{array}{l}\text { Water } \\
\text { level }\end{array}$ \\
\hline $11-14-85$ & 65
\end{tabular}


Table 3.-- Water levels in wells in Chambers County--Cont inued

Hell DH-64-13-601

Owner: Trinity Bay Conservation Dist. Well No. 1

Screen: 116-146 feet

Altitude: 26 feet

\begin{tabular}{cc}
\hline Date & $\begin{array}{c}\text { Water } \\
\text { level }\end{array}$ \\
\hline $11-14-85$ & 75.83 \\
$02-05-86$ & 70.47 \\
$03-20-87$ & 72.15 \\
$01-14-88$ & 63.46 \\
$01-05-89$ & 65.42
\end{tabular}

Well DH-64-13-602

Owner: Trinity Bay Conservation Dist.. Well No. 2

Screen: 117-147 feet

Altitude: 26 feet

\begin{tabular}{cc}
\hline Date & $\begin{array}{l}\text { Water } \\
\text { level }\end{array}$ \\
\hline $11-14-85$ & 77.48 \\
$02-05-86$ & 62.92 \\
$03-20-87$ & 63.73
\end{tabular}

Well DH-64-13-701

Owner: Harvey Haynes

Depth: 195 feet

Altitude: 23 feet

\begin{tabular}{cc}
\hline Date & $\begin{array}{l}\text { Water } \\
\text { level }\end{array}$ \\
\hline $11-14-85$ & 28.41 \\
$02-05-86$ & 30.67 \\
$03-20-87$ & 29.90 \\
$08-28-87$ & 28.69 \\
$01-14-88$ & 28.06 \\
$01-05-89$ & 30.40
\end{tabular}

Hell DH-64-17-311

Owner: Wilburn Bros.

Screen: 78-105 feet

Al titude: 23 feet

\begin{tabular}{cc}
\hline Date & $\begin{array}{c}\text { Water } \\
\text { level }\end{array}$ \\
\hline $02-04-85$ & 19.82 \\
$10-31-85$ & 20.20 \\
$01-31-86$ & 19.99 \\
$03-19-87$ & 19.50 \\
$08-26-87$ & 20.31 \\
$01-12-88$ & 20.64 \\
$01-04-89$ & 21.00
\end{tabular}

Well DH-64-17-901

Owner: Seacrest Park

Screen: 666-687 feet

Altitude: 25 feet

\begin{tabular}{cc}
\hline Date & $\begin{array}{l}\text { Water } \\
\text { level }\end{array}$ \\
\hline $02-04-85$ & 63.26 \\
$11-21-85$ & 62.90 \\
$01-31-86$ & 63.27 \\
$03-19-87$ & 62.02 \\
$08-26-87$ & 63.40 \\
$01-12-88$ & 63.29 \\
$01-04-89$ & 120.71
\end{tabular}

Well DH-64-21-205

Owner: Sun oil Co.

Depth: 150 feet

Altitude: 16 feet

\begin{tabular}{cc}
\hline Date & $\begin{array}{l}\text { Hater } \\
\text { level }\end{array}$ \\
\hline $11-14-85$ & 33.16 \\
$02-05-86$ & 32.28 \\
$03-20-87$ & 31.39 \\
$08-28-87$ & 32.58 \\
$01-14-88$ & 31.86 \\
$01-05-89$ & 29.97
\end{tabular}

Hell DH-64-26-401

Owner: Exxon Co. Hell No. is Depth: Unknown

Altitude: Sea level

\begin{tabular}{ll}
\hline Date & $\begin{array}{l}\text { Water } \\
\text { level }\end{array}$ \\
\hline $11-22-85$ & 91.90
\end{tabular}

Hell DH-64-26-701

Owner: Exxon Co., Well No. A-1

Screen: 610-671

Altitude: Sea level

\begin{tabular}{cc}
\hline Date & $\begin{array}{l}\text { Water } \\
\text { level }\end{array}$ \\
\hline $11-22-85$ & 83.47 \\
$04-09-87$ & 80.80 \\
$01-28-88$ & 80.28 \\
$01-06-89$ & 77.98
\end{tabular}




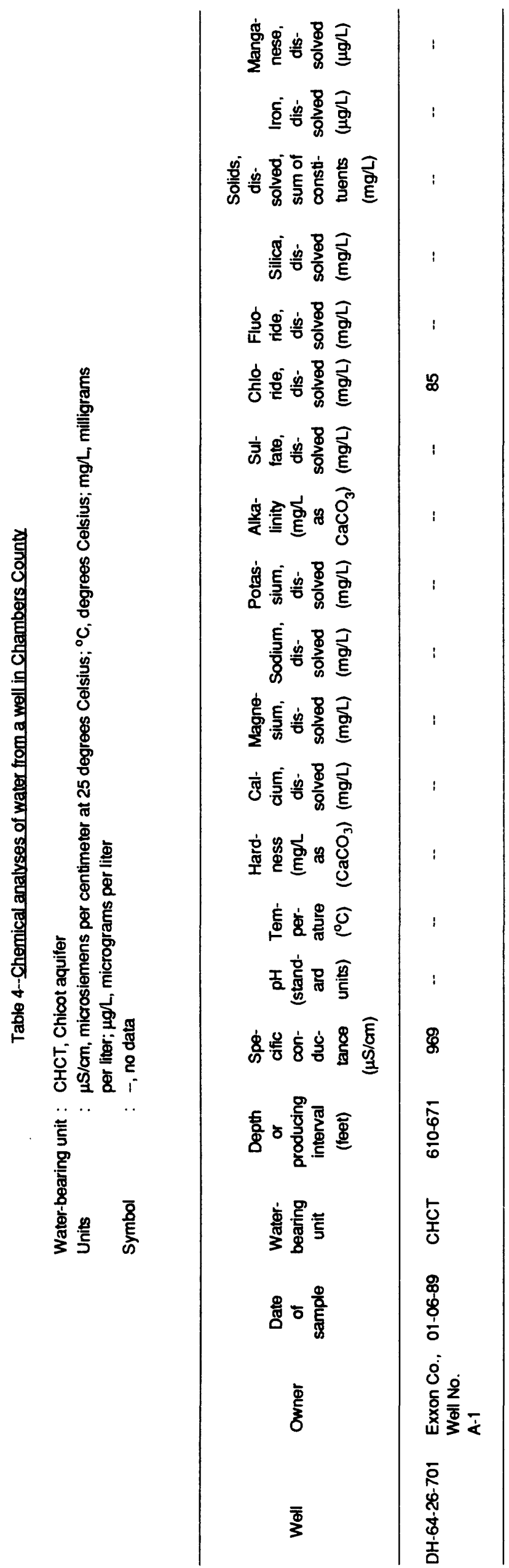




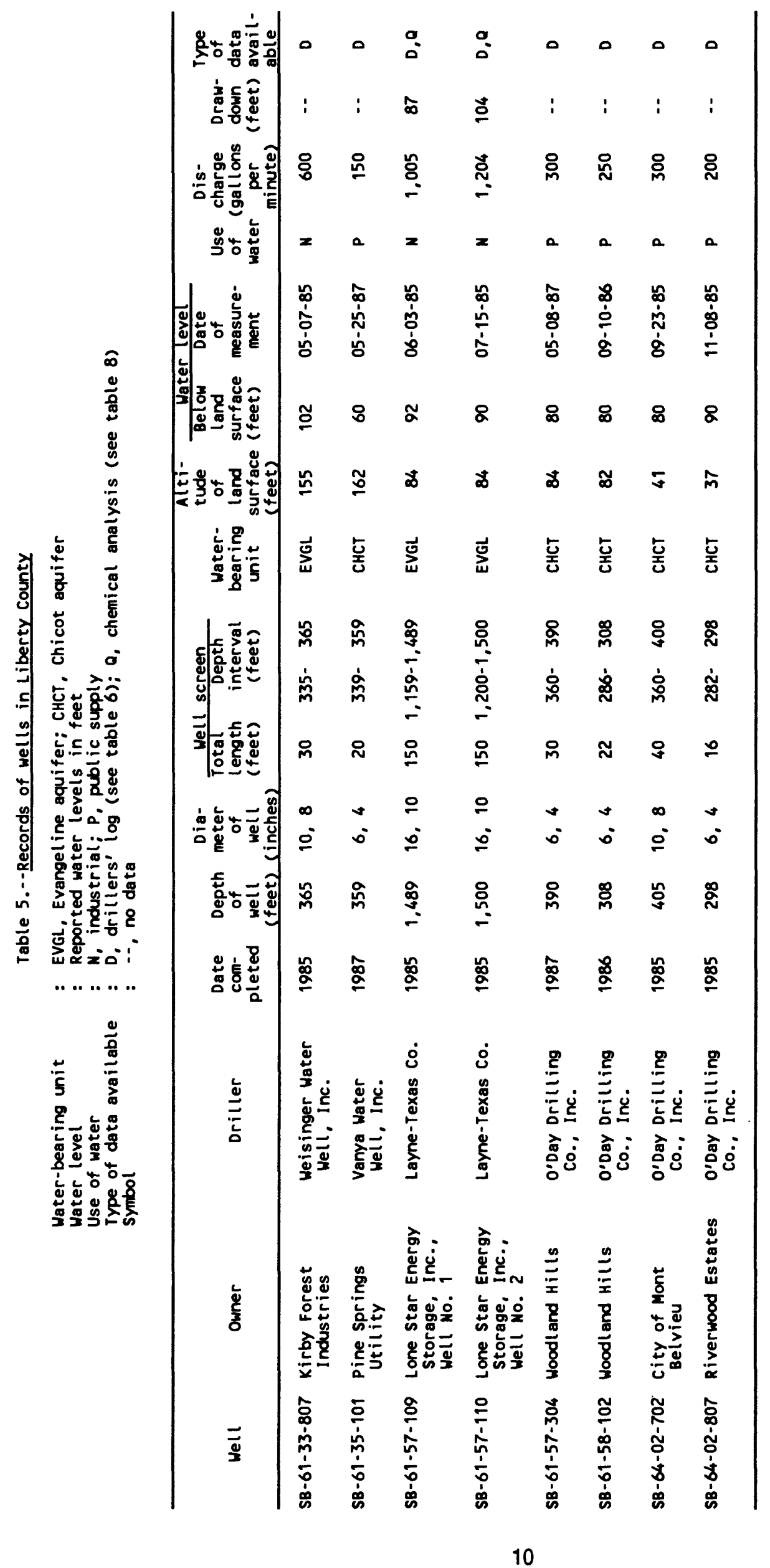


Table 6. - -Drillers' logs of wells in Liberty County

Well SB-61-33-807

Owner: Kirby Forest Industries

Driller: Heisinger Hater Hell, Inc.

\begin{tabular}{|c|c|c|}
\hline Description & $\begin{array}{l}\text { Thick- } \\
\text { ness } \\
\text { (feet) }\end{array}$ & $\begin{array}{l}\text { Depth } \\
\text { (feet) }\end{array}$ \\
\hline Clay & 30 & 30 \\
\hline Sand & 32 & 62 \\
\hline Sand and gravel & 18 & 80 \\
\hline Clay & 38 & 118 \\
\hline Rock & 4 & 122 \\
\hline $\mathrm{Clay}$ and rock & 53 & 175 \\
\hline Sand & 25 & 200 \\
\hline Rock & 2 & 202 \\
\hline $\mathrm{Clay}$ and rock & 23 & 225 \\
\hline Clay & 7 & 232 \\
\hline Sand & 36 & 268 \\
\hline Clay & 32 & 300 \\
\hline Sand & 24 & 324 \\
\hline Clay & 11 & 335 \\
\hline Sand & 30 & 365 \\
\hline
\end{tabular}

Well SB-61-35-101

Owner: Pine Springs Utility

Driller: Vanya Water Well, Inc.

\begin{tabular}{lcc}
\hline \multicolumn{1}{c}{ Description } & $\begin{array}{r}\text { Thick- } \\
\text { ness } \\
\text { (feet) }\end{array}$ & $\begin{array}{c}\text { Depth } \\
\text { (feet) }\end{array}$ \\
\hline Clay, red & 20 & 20 \\
Sand, red & 90 & 110 \\
Clay, wite & 110 & 220 \\
Sand, red & 31 & 251 \\
Clay, wite & 23 & 274 \\
Sand, wite & 14 & 288 \\
Clay, white & 23 & 319 \\
Sand, white, coarse & 8 & 319 \\
Clay & 14 & 333 \\
Sand, white & 26 & 359
\end{tabular}

Well SB-61-57-109

Owner: Lone Star Energy Storage, Inc., Well No. 1

Driller: Layne-Texas Co.

\begin{tabular}{|c|c|c|}
\hline Description & $\begin{array}{c}\text { Thick- } \\
\text { ness } \\
\text { (feet) }\end{array}$ & $\begin{array}{l}\text { Depth } \\
\text { (feet) }\end{array}$ \\
\hline Fill dirt & 0.5 & 0.5 \\
\hline Topsoil & 1.5 & 2 \\
\hline Clay & 5 & 7 \\
\hline $\mathrm{Clay}$ and sand streaks & 3 & 10 \\
\hline clay and sand & 4 & 14 \\
\hline Sand and clay streaks & 6 & 20 \\
\hline Clay & 2 & 22 \\
\hline Sand streaks, clay and sandy clay & 5 & 27 \\
\hline Clay & 8 & 35 \\
\hline Sand & 12 & 47 \\
\hline Clay & 2 & 49 \\
\hline Sand & 3 & 52 \\
\hline clay & 8 & 60 \\
\hline Clay, sandy clay & 2 & 62 \\
\hline Sand and clay streaks & 3 & 65 \\
\hline clay & 5 & 70 \\
\hline Clay, sandy clay & 2 & 72 \\
\hline Sand streaks & 5 & 77 \\
\hline Sand & 4 & 81 \\
\hline Clay & 11 & 92 \\
\hline Clay, sandy & 8 & 100 \\
\hline Sand & 14 & 114 \\
\hline Clay & 31 & 145 \\
\hline Clay and sandy streaks clay & 7 & 152 \\
\hline $\mathrm{Clay}$, sandy clay and sand streaks & 6 & 158 \\
\hline Clay & 17 & 175 \\
\hline $\mathrm{Clay}$ and sandy clay streaks & 9 & 184 \\
\hline Sand and gravel streaks & 8 & 192 \\
\hline Clay, sandy clay and gravel & 6 & 198 \\
\hline Clay & 9 & 207 \\
\hline Sand and gravel streaks & 29 & 236 \\
\hline Clay, sandy clay and sand & 7 & 243 \\
\hline Sand and gravel streaks & 22 & 265 \\
\hline Clay & 5 & 270 \\
\hline
\end{tabular}


Table 6.--Drillers' logs of wells in Liberty County--Cont inued

Well SB-61-57-109---Cont inued

Clay and sand

Clay

Clay and sandy clay

Sand

Clay

Sand

Clay and sand streaks

Sand and clay

Clay

Sand and clay streaks

Clay and sand streaks

Sand and a few clay streaks

Clay

Clay and sand streaks

Sand and clay streaks

Clay

Sand and clay

Sand and a few clay streaks

Sand, clay and shale

Clay

Clay, sandy and sand

Sand, lime and clay streaks

Clay

Clay and sandy clay

Sand, clay and lime

clay and lime

Clay

Clay and sandy clay

clay, sandy and sand streaks

Shale and sandy clay

Sand, shale streaks and gravel

clay, shale and lime

Clay, shale and lime streaks

Clay and shale

Clay

Lime streaks and clay

Sand, gravel streaks and clay streaks
Well SB-61-57-109--Cont inued

Clay, sandy, sand and clay streaks $13 \quad 829$

$\begin{array}{llll}\text { Clay } & 14 & 843\end{array}$

Clay and sandy clay $\quad 4 \quad 847$

Sand and gravel streaks $\quad 13 \quad 860$

Lime, hard, sand and gravel streaks 8

Clay and lime streaks $\quad 28 \quad 896$

Sand and clay streaks $\quad 5 \quad 901$

$\begin{array}{lll}\text { Sand } & 16 & 917\end{array}$

Clay $\quad 24 \quad 941$

Lime, hard, sand and clay streaks $\quad 19 \quad 960$

Lime, hard $\quad 2962$

Lime, hard and sand streaks 2

Lime, clay and sand $\quad 6 \quad 970$

Clay and sand $\quad 15 \quad 985$

Lime 11986

Clay $\quad 7 \quad 993$

Sand and clay $\quad 30 \quad 1,023$

Clay and sand streaks $\quad 11 \quad 1,034$

Clay and a few lime streaks $\quad 32 \quad 1,166$

Lime and clay

Lime

Lime and clay

Clay and shale

Sand, sandstone and shale streaks

Clay, shale and sandy clay streaks

Sand, clay, lime streaks and

sands tone

Clay, sand streaks and lime

Sand, lime, clay sandstone and gravel

Sand and lime streaks

Clay, sandy clay and lime streaks

Clay and lime

Clay and sand streaks

Hard lime streaks, sand and fine gravel

1,170

$5 \quad 1,175$

$5 \quad 1,180$

$5 \quad 1,185$

$42 \quad 1,227$

$85 \quad 1,312$

$34 \quad 1,346$

$4 \quad 1,350$

$17 \quad 1,367$

$2 \quad 1,369$

$3 \quad 1,372$

$14 \quad 1,386$

$2 \quad 9,388$

Clay and lime

Sand, hard lime and fine gravel

Lime streaks and clay

9

3

7

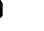

7

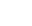

2


Table 6.--Drillers' logs of wells in Liberty County--Cont inued

Hell s8-61-57-109--Cont inued

Clay, lime streaks and sandy clay $\quad 10 \quad 1,455$

Sand, clay streaks, gravel and lime $32 \quad 1,487$

Lime

Sand

Clay

Hell SB-61-57-110

Owner: Lone Star Energy Storage, Inc., Well No. 2

Driller: Layne-Texas Co.

\begin{tabular}{|c|c|c|}
\hline Description & $\begin{array}{l}\text { Thick- } \\
\text { ness } \\
\text { (feet) }\end{array}$ & $\begin{array}{l}\text { Depth } \\
\text { (feet) }\end{array}$ \\
\hline Fill & 0.5 & 0.5 \\
\hline Topsoil & 1.5 & 2 \\
\hline Clay & 8 & 10 \\
\hline Sandy and clay streaks & 4 & 14 \\
\hline Clay & 8 & 22 \\
\hline Sand and clay streaks & 4 & 26 \\
\hline Clay & 8 & 34 \\
\hline Sand & 13 & 47 \\
\hline Clay & 17 & 64 \\
\hline Sand and clay streaks & 3 & 67 \\
\hline Clay and sandy clay streaks & 8 & 75 \\
\hline Sand and clay streaks & 7 & 82 \\
\hline Clay and sandy clay streaks & 36 & 118 \\
\hline clay & 12 & 130 \\
\hline Sand & 19 & 149 \\
\hline Clay & 33 & 182 \\
\hline Sand and clay & 4 & 186 \\
\hline clay & 17 & 203 \\
\hline Sand and clay streaks & 28 & 231 \\
\hline Clay and sandy clay & 6 & 237 \\
\hline Sand and clay streaks & 13 & 250 \\
\hline Sand & 16 & 266 \\
\hline Clay, sandy clay and sand streaks & 5 & 271 \\
\hline Sand & 6 & 277 \\
\hline Clay & 21 & 298 \\
\hline Clay, sandy clay and sand streaks & 15 & 313 \\
\hline Sand and $\mathrm{clay}$ streaks & 17 & 330 \\
\hline Clay & 3 & 333 \\
\hline
\end{tabular}

Well SB-61-57-110--Cont inued

Clay and sand 8

341

Sand and a few clay streaks $\quad 14 \quad 355$

Sand and clay streaks $\quad 17 \quad 372$

Clay $\quad 14 \quad 386$

Sand $\quad 16 \quad 402$

Sand and clay $\quad 4 \quad 406$

Sand

Clay and sand streaks $\quad 16 \quad 429$

Sand and clay streaks $\quad 64 \quad 493$

Clay and a few sand streaks $\quad 11 \quad 504$

Sand and clay $\quad 8 \quad 512$

Sand and a few clay streaks $\quad 14 \quad 526$

Clay $\quad 8 \quad 534$

Sand and clay streaks $\quad 31 \quad 565$

Clay and sand $\quad 11 \quad 576$

Clay $\quad 26 \quad 602$

Sand and clay $\quad 11 \quad 613$

Clay $\quad 19 \quad 632$

Clay and sandy clay streaks $\quad 14 \quad 646$

Sand $\quad 4 \quad 650$

Clay and lime streaks $\quad 4 \quad 654$

Sand, gravel, lime and clay streaks $21 \quad 675$

Lime $\quad 2 \quad 67$

Sand and clay streaks $\quad 13 \quad 690$

$\begin{array}{lll}\text { Clay and a few sand streaks } & 20 & 710\end{array}$

Sand, clay and gravel streaks $\quad 26 \quad 736$

Clay and sandy clay $\quad 4 \quad 740$

Clay and lime streaks $\quad 40 \quad 780$

Clay and sandy clay $\quad 9789$

Sand, gravel and clay streaks $\quad 31 \quad 820$

Lime $\quad 3 \quad 823$

Sand and lime streaks $\quad 5 \quad 828$

Lime $\quad 2 \quad 830$

Sand, lime and clay streaks $\quad 17 \quad 847$

Clay and lime streaks $\quad 10 \quad 857$

Clay 11858

$\begin{array}{lll}\text { Sand } & 25 & 883\end{array}$

Clay, sand and clay streaks $\quad 5 \quad 888$ 
Table 6.--Drillers' logs of wells in Liberty County--Cont inued

Well SB-61-57-110--Cont inued

Clay, sandy clay and sand breaks

Clay and shale streaks

Sand

$\mathrm{Clay}$

Sand and gravel

Clay and lime streaks

Sand, gravel and lime streaks

Lime, hard

Sand, gravel and lime streaks

Sand, gravel and clay streaks

Clay and lime streaks

Clay, sand and clay streaks

Sand and clay streaks

Sand, gravel and clay streaks

Clay

Sand, sandy clay and clay streaks

Sand, gravel, lime and clay streaks

Clay and lime streaks

Lime, hard

Clay and lime streaks

Clay and sandy clay

Clay and lime streaks

Clay

Clay and shale streaks

Sand and clay

Clay, shale, lime and sand streaks

Clay

Sand, clay and lime streaks

Lime

Sand, clay and lime streaks

Lime and clay

Sand and clay

Lime and clay

Clay and sand

Lime

Clay

Lime

clay
5

14

4

2

27

17$$
4
$$$$
1
$$$$
9
$$$$
8
$$$$
2
$$

28

12

12

20

10

20

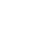

$4 \quad 1,085$

$4 \quad 1,089$

$29 \quad 1,118$

$32 \quad 1,150$

$44 \quad 1,194$

$7 \quad 1,201$

$17 \quad 1,218$

$6 \quad 1,224$

$3 \quad 1,227$

$1 \quad 1,228$

21,230

21,232

$3 \quad 1,235$

$1 \quad 1,236$

$2 \quad 1,238$

21,240

$16 \quad 1,256$

$1 \quad 1,257$

$73 \quad 1,330$
Well SB-61-57-110--Cont inued

$\begin{array}{lrr}\text { Clay and lime } & 3 & 1,333 \\ \text { Lime, hard } & 3 & 1,336 \\ \text { Clay and lime streaks } & 7 & 1,343 \\ \text { Sand, lime, gravel and clay streaks } & 28 & 1,371 \\ \text { Lime, hard } & 2 & 1,373 \\ \text { Sand } & 1 & 1,374 \\ \text { Lime } & 1 & 1,375 \\ \text { Sand } & 1 & 1,376 \\ \text { Lime } & 2 & 1,378 \\ \text { Lime and sandy streaks } & 4 & 1,382 \\ \text { Sand, lime, clay streaks and gravel } & 40 & 1,422 \\ \text { clay and lime streaks } & 33 & 1,455 \\ \text { Lime } & 2 & 1,457 \\ \text { Lime and sand streaks } & 5 & 1,462 \\ \text { Sand, lime, clay streaks and gravel } & 39 & 1,501 \\ \text { Lime } & 2 & 1,503 \\ \text { Lime and clay } & 2 & 1,505\end{array}$

Well SB-61-57-304

Omer: Woodland Hills

Driller: O'Day Drilling Co., Inc.

\begin{tabular}{|c|c|c|}
\hline Description & $\begin{array}{l}\text { Thick- } \\
\text { ness } \\
\text { (feet) }\end{array}$ & $\begin{array}{l}\text { Depth } \\
\text { (feet) }\end{array}$ \\
\hline Topsoil & 3 & 3 \\
\hline Clay & 63 & 66 \\
\hline Sand & 22 & 88 \\
\hline Clay & 133 & 221 \\
\hline Sand & 17 & 238 \\
\hline Clay & 11 & 249 \\
\hline Sand & 12 & 261 \\
\hline Clay & 99 & 360 \\
\hline Sand & 30 & 390 \\
\hline \multicolumn{3}{|c|}{$\begin{array}{l}\text { Mell SB-61-58-102 } \\
\text { Owner: Woodland Hills } \\
\text { Driller: O'Day Drilling Co., Inc. }\end{array}$} \\
\hline Description & $\begin{array}{c}\text { Thick- } \\
\text { ness } \\
\text { (feet) }\end{array}$ & $\begin{array}{l}\text { Depth } \\
\text { (feet) }\end{array}$ \\
\hline Topsoil & 3 & 3 \\
\hline Clay & 63 & 66 \\
\hline Sand & 21 & 87 \\
\hline
\end{tabular}


Table 6. --Drillers' logs of wells in Liberty County--Cont inued

Well SB-61-58-102--Cont inued

Clay

Sand

Clay

Sand

Sand and clay

Well SB-64-02-702

Owner: City of Mont Belvieu

Driller: O'Day Drilling Co., Inc.

\begin{tabular}{lrc}
\hline Description & $\begin{array}{r}\text { Thick- } \\
\text { ness } \\
\text { (feet) }\end{array}$ & $\begin{array}{c}\text { Depth } \\
\text { (feet) }\end{array}$ \\
\hline Topsoil & 3 & 3 \\
Clay & 75 & 78 \\
Sand & 3 & 81 \\
Clay & 19 & 100 \\
Sand & 5 & 105 \\
Clay & 17 & 122 \\
Sand and clay & 8 & 130 \\
Clay & 40 & 170 \\
Sand and clay & 5 & 175 \\
Clay & 17 & 192 \\
Sand & 3 & 195 \\
Clay & 40 & 235
\end{tabular}

Well SB-64-02-702--Continued

\begin{tabular}{|c|c|c|c|}
\hline 46 & 133 & Sand & 6 \\
\hline 28 & 161 & Clay & 3 \\
\hline 122 & 283 & Sand & 10 \\
\hline 19 & 302 & Clay & 12 \\
\hline \multirow[t]{4}{*}{10} & 312 & Sand & 22 \\
\hline & & Clay & 9 \\
\hline & & Sand & 3 \\
\hline & & Clay & 56 \\
\hline $\begin{array}{l}\text { ness } \\
\text { feet) }\end{array}$ & $\begin{array}{l}\text { Depth } \\
\text { (feet) }\end{array}$ & Sand & 44 \\
\hline & & Clay & 10 \\
\hline
\end{tabular}

Well SB-64-02-807

Owner: Riverwood Estates

Driller: O'Day Drilling Co., Inc.

\begin{tabular}{lcc}
\hline Description & $\begin{array}{c}\text { Thick- } \\
\text { ness } \\
\text { (feet) }\end{array}$ & $\begin{array}{c}\text { Depth } \\
\text { (feet) }\end{array}$ \\
\hline Topsoil & 3 & 3 \\
Clay & 17 & 20 \\
Sand & 13 & 33 \\
Clay & 57 & 90 \\
Sand & 15 & 105 \\
Clay & 175 & 280 \\
Sand & 18 & 298 \\
\hline
\end{tabular}


Table 7.-- Water levels in wells in Liberty County

Depth : Depth of well

Altitude : Altitude of land surface above sea level

Screen : Top and bottom of screened interval below land surface

Hater level: Measured by the U.S. Geological Survey in hundredths of feet below land surface

Hell SB-60-48-302

Owner: Vernon El ledge, Well No. 2

Depth: 452 feet

Altitude: 153 feet

\begin{tabular}{cc}
\hline Date & $\begin{array}{l}\text { Water } \\
\text { level }\end{array}$ \\
\hline $10-23-85$ & 20.32 \\
$04-14-86$ & 18.28 \\
$03-27-87$ & 11.32 \\
$01-30-89$ & 17.65
\end{tabular}

Well SB-60-56-901

Owner: E.J. Stoesser. Hell No. 3

Depth: 1,015 feet

Altitude: 86 feet

\begin{tabular}{cc}
\hline Date & $\begin{array}{c}\text { Water } \\
\text { level }\end{array}$ \\
\hline $02-11-85$ & 74.75 \\
$02-03-86$ & 70.78 \\
$01-06-87$ & 78.28 \\
$01-26-89$ & 80.66
\end{tabular}

Well SB-60-56-902

Owner: E.J. Stoesser, Well No. 5

Depth: 1,040 feet

Altitude: 85 feet

\begin{tabular}{ll}
\hline Water & Hater \\
level
\end{tabular}

$01-26-89 \quad 86.76$

Hell SB-60-64-301

Orner: E.J. Stcesser, Hell No. 2

Depth: 1,006 feet

Altitude: 82 feet

\begin{tabular}{cc}
\hline Date & $\begin{array}{l}\text { Water } \\
\text { level }\end{array}$ \\
\hline $02-11-85$ & 78.75 \\
$02-03-86$ & 76.31 \\
$01-26-89$ & 78.64
\end{tabular}

Hell SB-60-64-303

Owner: E.J. Stoesser, Well No. 6

Screen: 203-580 feet

Altitude: 85 feet

\begin{tabular}{cc}
\hline Date & $\begin{array}{l}\text { Water } \\
\text { level }\end{array}$ \\
\hline $02-11-85$ & 79.57 \\
$02-03-86$ & 68.00 \\
$01-06-87$ & 72.20 \\
$01-26-89$ & 73.76
\end{tabular}

Well SB-60-64-602

Owner: E.J. Stoesser, Nell No. 4 Depth: 1,017 feet

Al titude: 83 feet

\begin{tabular}{cc}
\hline Date & $\begin{array}{c}\text { Hater } \\
\text { level }\end{array}$ \\
\hline $02-03-86$ & 113.42 \\
$01-08-88$ & 119.85 \\
$01-26-89$ & 126.90
\end{tabular}

Well SB-61-33-701

Owner: Roy Elledge

Depth: 835 feet

Altitude: 157 feet

\begin{tabular}{|c|c|}
\hline Date & $\begin{array}{l}\text { Water } \\
\text { level }\end{array}$ \\
\hline $\begin{array}{l}10-23-85 \\
04-14-86 \\
03-27-87\end{array}$ & $\begin{array}{l}32.46 \\
32.70 \\
32.99\end{array}$ \\
\hline
\end{tabular}

Well SB-61-41-101

Owner: Vernon Elledge

Depth: 502 feet

Altitude: 153 feet

\begin{tabular}{cc}
\hline Date & $\begin{array}{l}\text { Water } \\
\text { level }\end{array}$ \\
\hline $10-23-85$ & 34.45 \\
$04-14-86$ & 32.83 \\
$03-27-87$ & 31.86 \\
$01-30-89$ & 37.57
\end{tabular}

Well SB-61-41-701

Owner: M.A. Scott

Depth: 625 feet

Altitude: 128 feet

\begin{tabular}{cc}
\hline Date & $\begin{array}{l}\text { Water } \\
\text { level }\end{array}$ \\
\hline $10-21-85$ & 47.17 \\
$04-14-86$ & 46.34 \\
$04-10-87$ & 61.28 \\
$01-30-89$ & 55.17
\end{tabular}

Well SB-61-43-801

Owner: A.L. Erickson

Depth: 100 feet

Altitude: 93 feet

\begin{tabular}{cc}
\hline Date & $\begin{array}{l}\text { Water } \\
\text { level }\end{array}$ \\
\hline $04-14-86$ & 44.80
\end{tabular}

Well SB-61-49-807

Owner: Bol inger Bros.

Screen: $65-396$ feet

Altitude: 97 feet

\begin{tabular}{cc}
\hline Date & $\begin{array}{c}\text { Water } \\
\text { level }\end{array}$ \\
\hline $11-12-85$ & 92.39 \\
$04-08-86$ & 95.72 \\
$04-10-87$ & 89.23 \\
$09-21-87$ & 88.43 \\
$01-08-88$ & 92.78 \\
$01-27-89$ & 96.51
\end{tabular}

Yell SB-61-51-101

Owner: Dennison

Depth: 1,150 feet

Altitude: 95 feet

\begin{tabular}{cc}
\hline Date & $\begin{array}{c}\text { Water } \\
\text { level }\end{array}$ \\
\hline $11-12-85$ & 51.48 \\
$04-14-86$ & 50.47 \\
$03-27-87$ & 49.50 \\
$01-27-89$ & 49.57
\end{tabular}

Hell SB-61-51-102

Owner: Frank Duke

Depth: 660 feet

Alt i tude: 87 feet

\begin{tabular}{cc}
\hline Date & $\begin{array}{l}\text { Water } \\
\text { level }\end{array}$ \\
\hline $11-12-85$ & 44.21 \\
$04-14-86$ & 43.31 \\
$03-27-87$ & 39.88 \\
$01-27-89$ & 44.58
\end{tabular}

Well SB-61-59-806

Owner: Morgan Tippett

Depth: 624 feet

Altitude: 68 feet

\begin{tabular}{cc}
\hline Date & $\begin{array}{l}\text { Mater } \\
\text { level }\end{array}$ \\
\hline $11-12-85$ & 31.64 \\
$04-08-86$ & 28.61 \\
$04-10-87$ & 29.91 \\
$01-27-89$ & 31.51
\end{tabular}

Well SB-61-57-506

Owner: H.M. Moreau

Depth: 940 feet

Altitude: 78 feet

\begin{tabular}{cc}
\hline Date & $\begin{array}{c}\text { Water } \\
\text { level }\end{array}$ \\
\hline $02-11-85$ & 111.83 \\
$11-12-85$ & 114.51 \\
$04-08-86$ & 104.82 \\
$01-12-87$ & 105.33 \\
$01-08-88$ & 112.20 \\
$01-26-89$ & 117.98
\end{tabular}


Table 7.-- Hater levels in wells in Liberty County--Cont inued

Well SB-61-57-702

Owner: J.M. Frost, Jr., Well No. 1

Depth: 800 feet

Altitude: 67 feet

\begin{tabular}{cc}
\hline Date & $\begin{array}{c}\text { Water } \\
\text { level }\end{array}$ \\
\hline $02-11-85$ & 102.05 \\
$04-08-86$ & 104.81 \\
$01-12-87$ & 105.79 \\
$01-26-89$ & 99.32
\end{tabular}

Well SB-61-57-703

Owner: J.M . Frost, Jr., Well No. 2

Screen: $240-837$ feet

Alt itude: 67 feet

\begin{tabular}{ll}
\hline Dater & $\begin{array}{l}\text { Hater } \\
\text { level }\end{array}$ \\
\hline
\end{tabular}

$02-11-85 \quad 113.32$

$11-07-85 \quad 110.04$

04-08-86 $\quad 113.25$

$01-12-87 \quad 116.95$

$01-08-88 \quad 103.78$

$\begin{array}{ll}01-26-89 & 106.87\end{array}$
Well SB-61-58-505

Owner: Charles W. Fisher

Depth: 651 feet

Altitude: 30 feet

\begin{tabular}{ll}
\hline Date & Hater \\
level
\end{tabular}

$11-12-85$

44.63

04-08-86 $\quad 38.56$

$04-10-87 \quad 34.67$

09-21-87 35.12

01-27-89 38.65

Well SB-61-59-106

Owner: Graves and Partlow

Depth: 485 feet

Altitude: 72 feet

\begin{tabular}{ll}
\hline Date & $\begin{array}{l}\text { Water } \\
\text { level }\end{array}$ \\
\hline
\end{tabular}

$01-27-89 \quad 42.22$
Well SB-61-59-501

Owner: C.F. Kall ine

Depth: 1,180 feet Altitude: 66 feet

\begin{tabular}{cc}
\hline Date & $\begin{array}{l}\text { Water } \\
\text { level }\end{array}$ \\
\hline $11-12-85$ & 51.33 \\
$04-08-86$ & 47.93 \\
$04-10-87$ & 49.81 \\
$01-27-89$ & 48.17
\end{tabular}




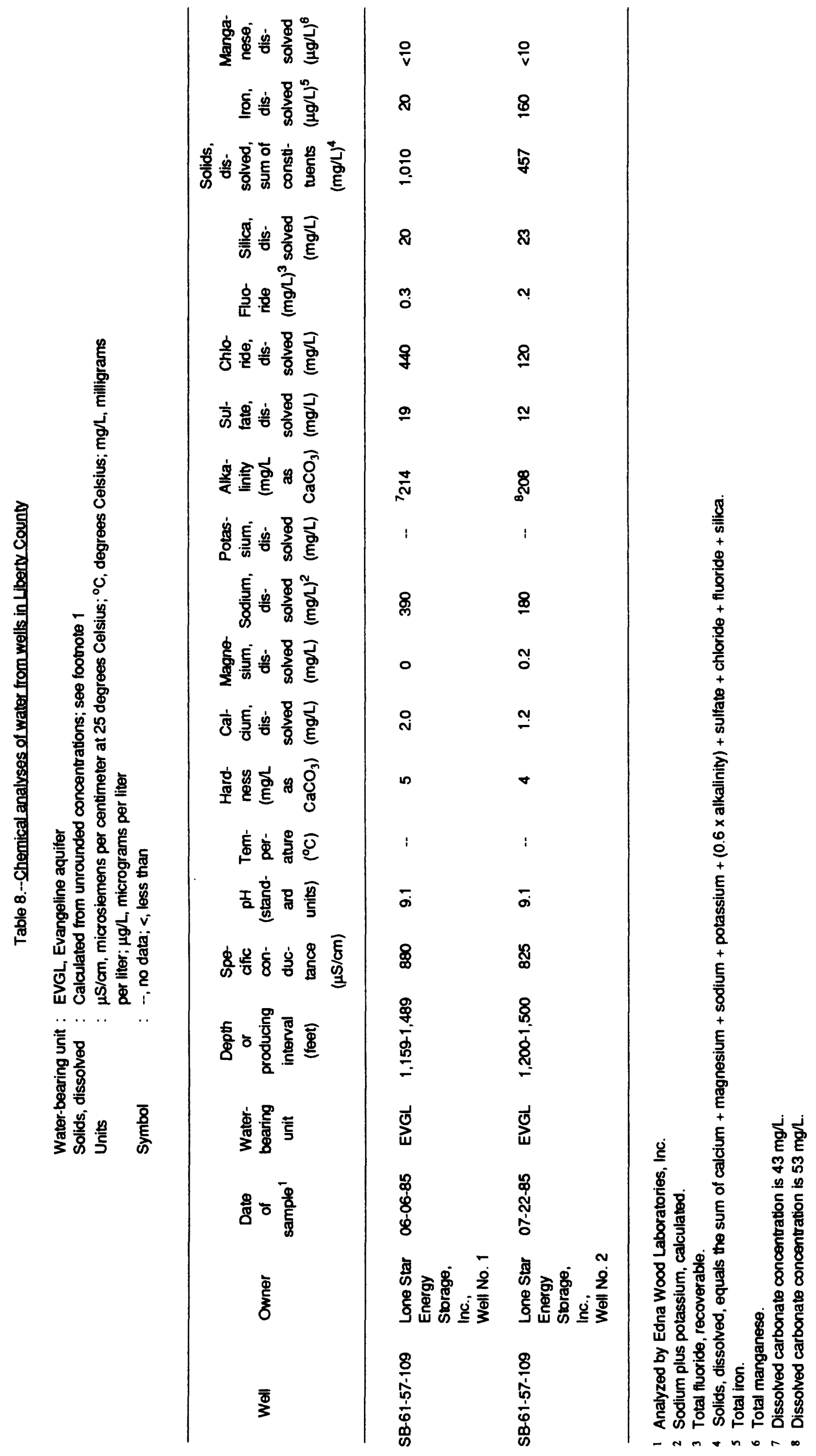




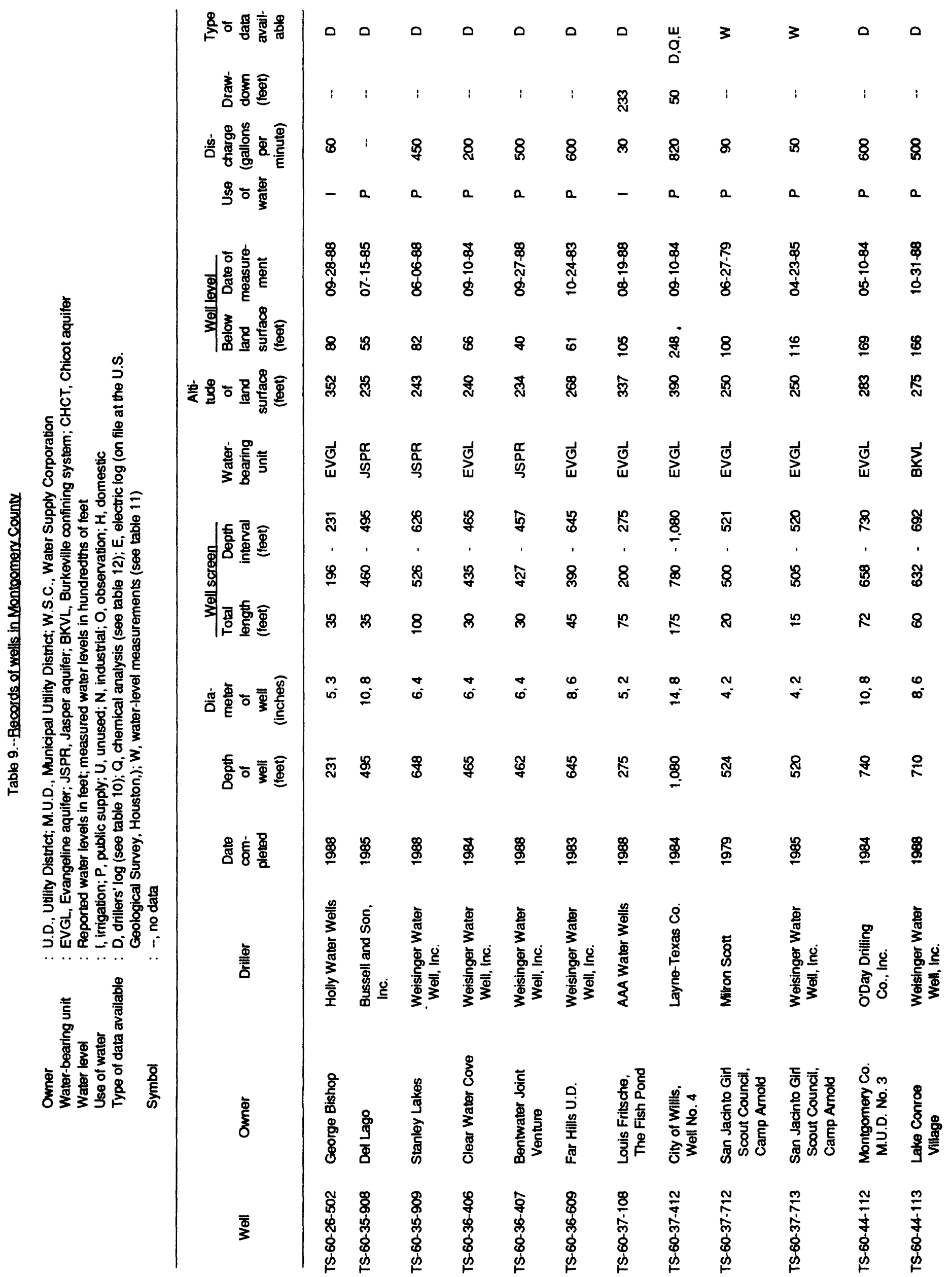




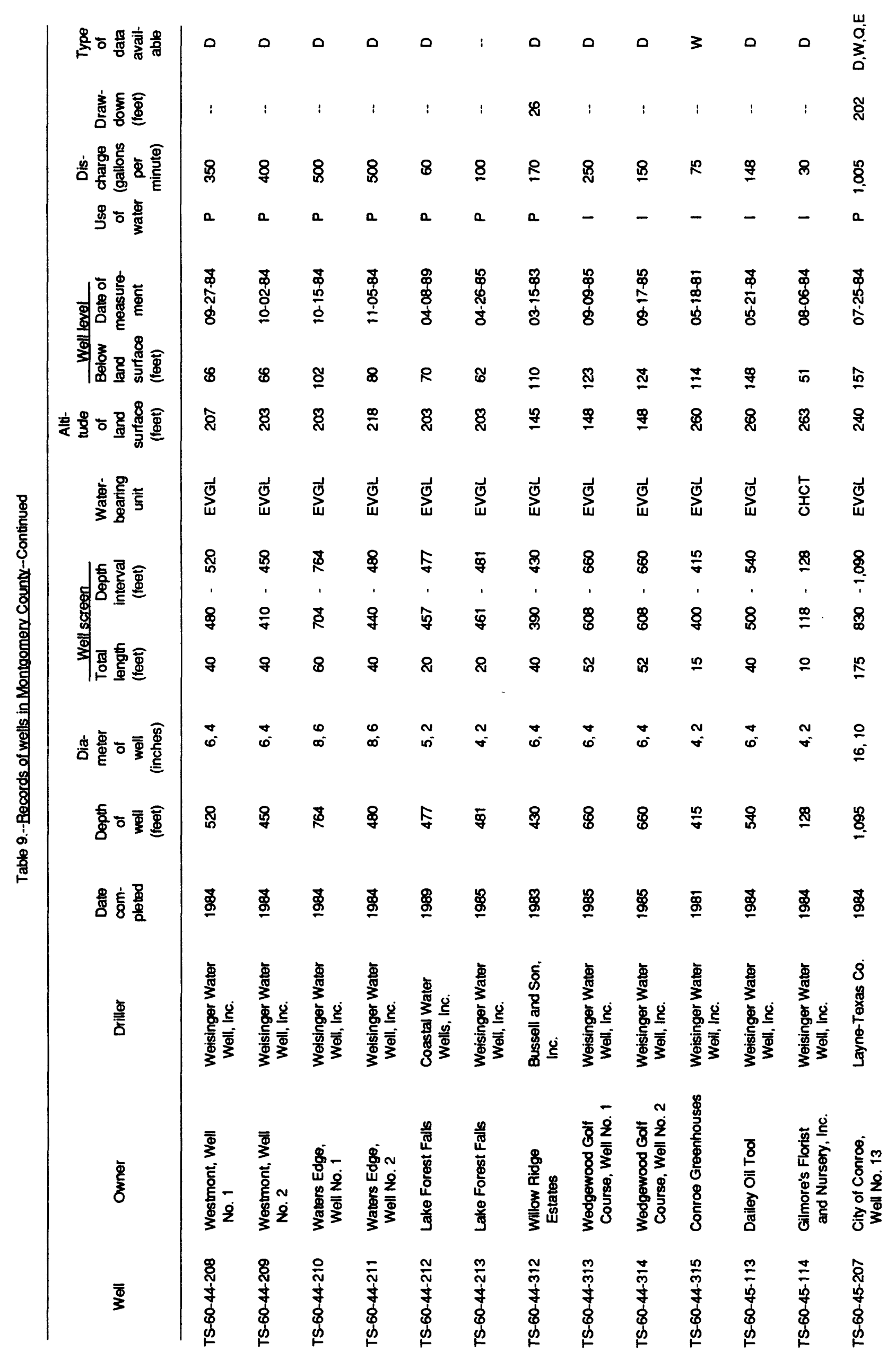




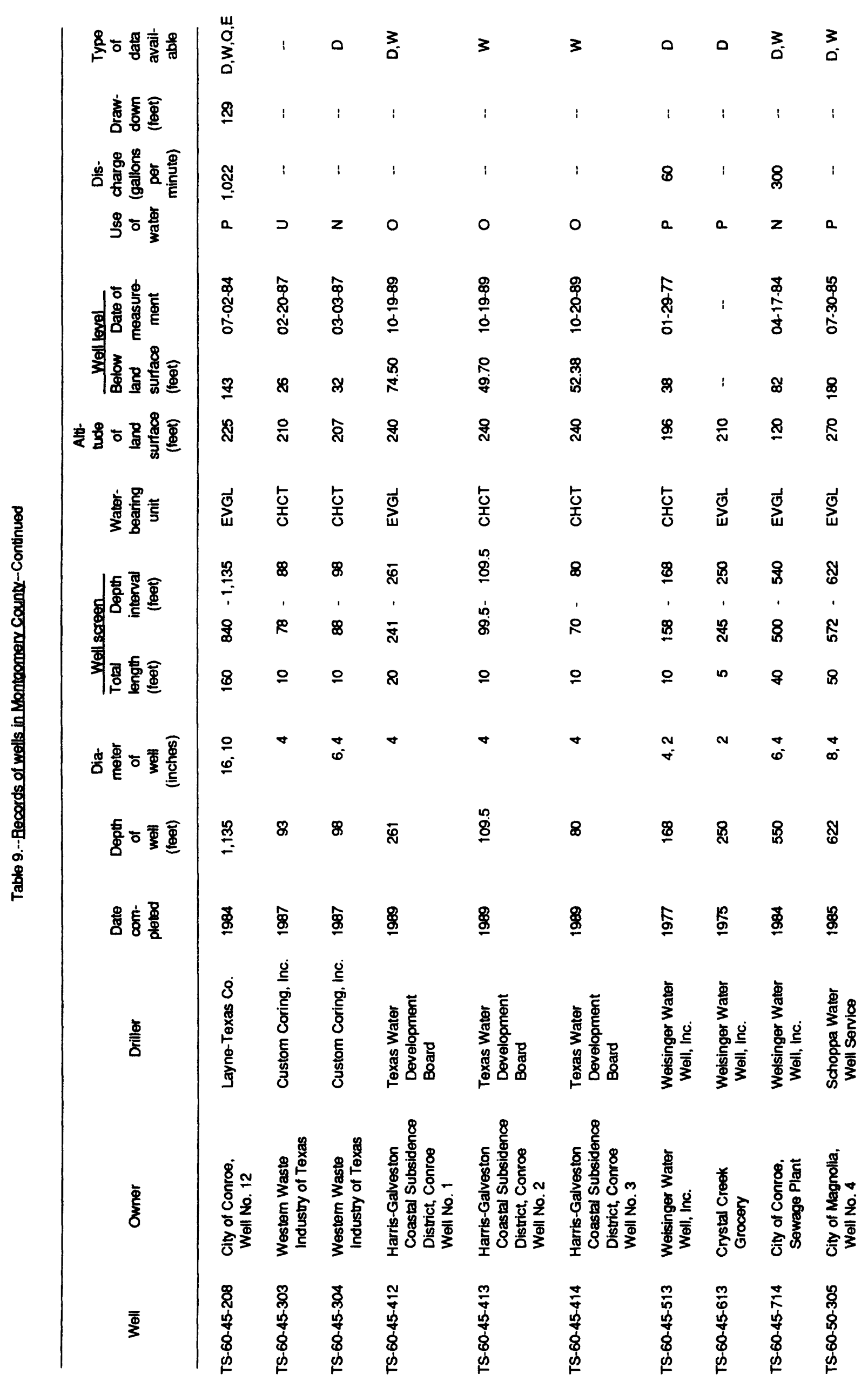




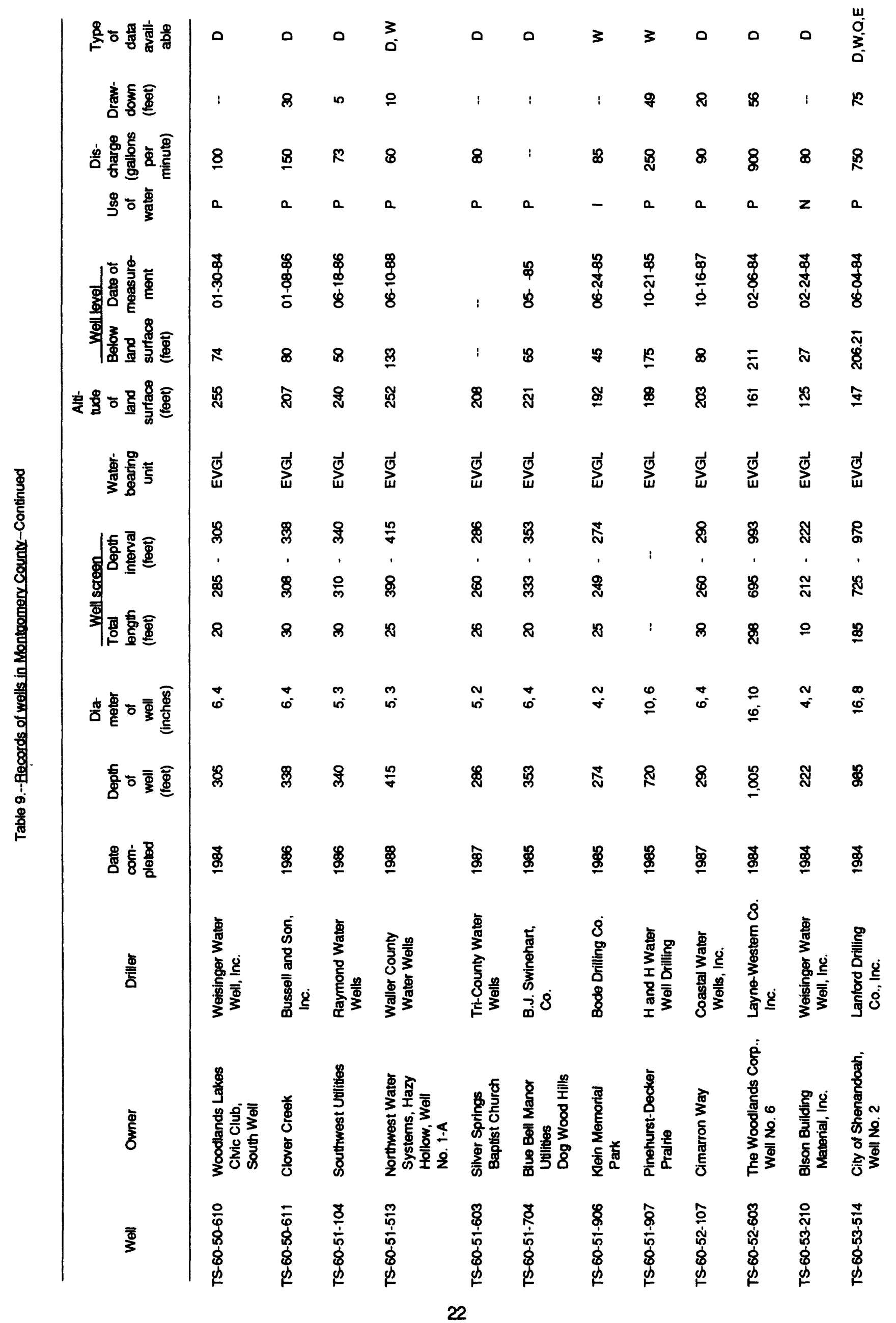




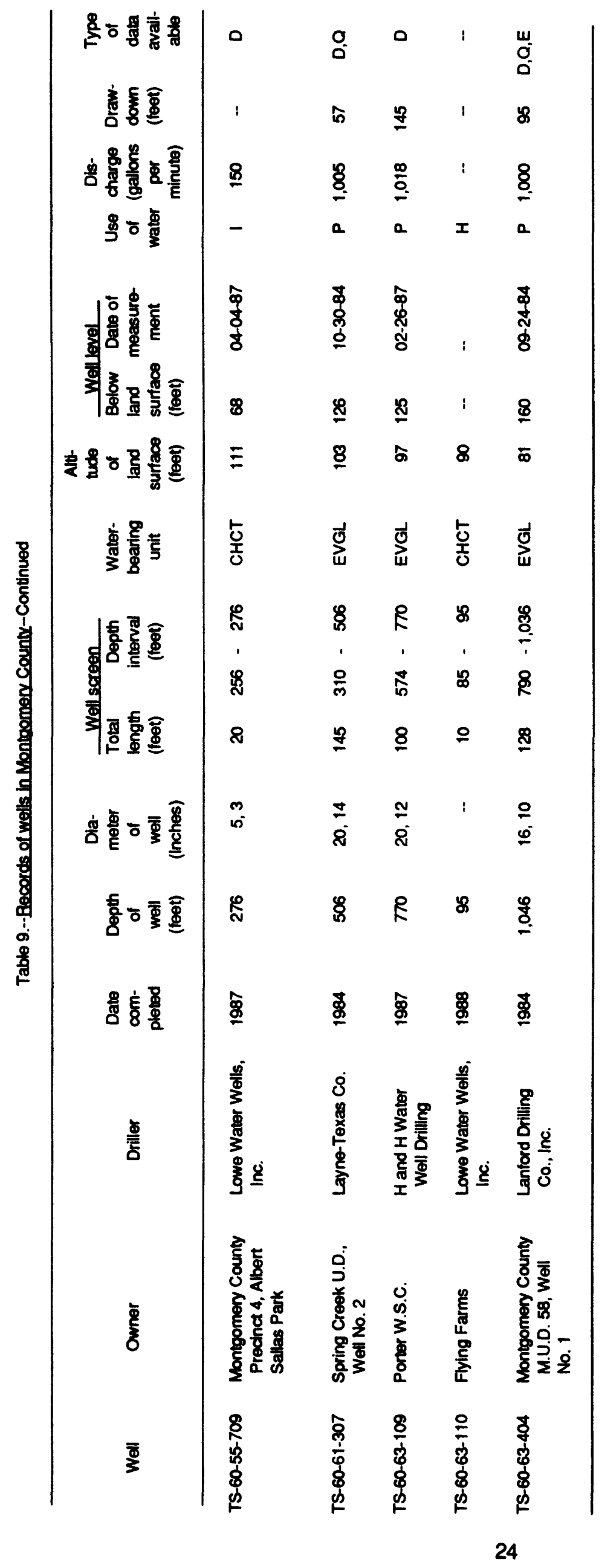


Table 10.--Drillers' logs of wells in Montgomery County

Owner: U.D., Utility Distrit; M.U.D., Municipal Utility District; W.S.C., Water Supply Corporation symbol: $\cdots$, Lithology is less than 1 foot in thickness

Well TS-60-26-502

Owner: George Bishop

Driller: Holly Water Hells

\begin{tabular}{|c|c|c|}
\hline Description & $\begin{array}{l}\text { Thick- } \\
\text { ness } \\
\text { (feet) }\end{array}$ & $\begin{array}{l}\text { Depth } \\
\text { (feet) }\end{array}$ \\
\hline Topsoil & 4 & 4 \\
\hline Clay, mealy & 20 & 24 \\
\hline Clay, white & 10 & 34 \\
\hline Clay, blue & 10 & 44 \\
\hline Clay, mealy and sand streaks & 20 & 64 \\
\hline Clay, mealy & 40 & 104 \\
\hline Sand streaks & 20 & 124 \\
\hline Clay, mealy & 8 & 132 \\
\hline Rock and sand streaks & 12 & 144 \\
\hline Clay, blue & 10 & 154 \\
\hline Sand streaks & 22 & 176 \\
\hline Sand & 38 & 214 \\
\hline Sand and gravel & 17 & 231 \\
\hline \multicolumn{3}{|l|}{$\begin{array}{l}\text { Well Ts-60-35-908 } \\
\text { Owner: Del Lago } \\
\text { Driller: Bussell and Son, Inc. }\end{array}$} \\
\hline Description & $\begin{array}{l}\text { Thick- } \\
\text { ness } \\
\text { (feet) }\end{array}$ & $\begin{array}{l}\text { Depth } \\
\text { (feet) }\end{array}$ \\
\hline Sand and clay streaks & 272 & 272 \\
\hline Clay & 188 & 460 \\
\hline Sand & 22 & 482 \\
\hline Clay & 4 & 486 \\
\hline Sand & 14 & 500 \\
\hline $\mathrm{Clay}$ & 3 & 503 \\
\hline
\end{tabular}

Well TS-60-35-909

Omer: Stanley Lakes

Driller: Heisinger Water Hell, Inc.

\begin{tabular}{lcc}
\hline Description & $\begin{array}{c}\text { Thick- } \\
\text { ness } \\
\text { (feet) }\end{array}$ & $\begin{array}{c}\text { Depth } \\
\text { (feet) }\end{array}$ \\
\hline Clay & 58 & 58 \\
Rock & 6 & 64 \\
Sand & 4 & 68 \\
Clay & 20 & 88 \\
Sand & 38 & 126 \\
Clay & 7 & 133
\end{tabular}

Well TS-60-35-909--Cont inued

Sand $\quad 21 \quad 154$

Clay $32 \quad 186$

Sand $\quad 40 \quad 226$

Clay $\quad 35 \quad 261$

Sand $\quad 25 \quad 286$

Clay $\quad 240 \quad 526$

Rock $\quad 4 \quad 530$

Sand $\quad 53 \quad 583$

Clay $\quad 5 \quad 588$

Sand $\quad 4 \quad 592$

Sand and clay $\quad 12 \quad 604$

$\begin{array}{lll}\text { Sand } & 8 & 612\end{array}$

Sand and clay $\quad 4 \quad 616$

Sand and rock $\quad 9 \quad 625$

$\begin{array}{lll}\mathrm{Clay} & 23 & 648\end{array}$

Well Ts-60-36-406

Owner: Clear Water Cove

Driller: Weisinger Water Well, Inc.

\begin{tabular}{lrc}
\hline Description & $\begin{array}{c}\text { Thick- } \\
\text { ness } \\
\text { (feet) }\end{array}$ & $\begin{array}{c}\text { Depth } \\
\text { (feet) }\end{array}$ \\
\hline Clay & 100 & 100 \\
Sand and rock & 15 & 115 \\
Clay with rock & 50 & 165 \\
Sand & 15 & 180 \\
Clay & 15 & 195 \\
Sand & 35 & 230 \\
Clay & 70 & 300 \\
Sand & 37 & 337 \\
Sand with clay & 8 & 345 \\
Clay & 50 & 395 \\
Sand, coarse & 70 & 465
\end{tabular}

Well Ts-60-36-407

Owner: Bentwater Joint Venture

Driller: Weisinger Water Well, Inc.

\begin{tabular}{lcc}
\hline Description & $\begin{array}{c}\text { Thick- } \\
\text { ness } \\
\text { (feet) }\end{array}$ & $\begin{array}{c}\text { Depth } \\
\text { (feet) }\end{array}$ \\
\hline Clay & 18 & 18 \\
Sand & 21 & 39
\end{tabular}


Table 10.--Drillers' logs of wells in Montgomery County---Cont inued

Well is-60-36-407--Continued

Clay and rock

Sand

Clay

Sand

Clay

Sand

Clay

Sand

Clay

Sand

Clay

Clay

Sand

Well TS-60-36-609

Omer: Far Hills U.D.

Driller: Heisinger Water Hell, Inc.

\begin{tabular}{|c|c|c|}
\hline Description & $\begin{array}{c}\text { Thick- } \\
\text { ness } \\
\text { (feet) }\end{array}$ & $\begin{array}{l}\text { Depth } \\
\text { (feet) }\end{array}$ \\
\hline Clay and rock & 45 & 45 \\
\hline Rock & 3 & 48 \\
\hline Clay & 62 & 110 \\
\hline Rock & 3 & 113 \\
\hline $\mathrm{Clay}$ & 20 & 133 \\
\hline Rock & 2 & 135 \\
\hline $\mathrm{Clay}$ & 55 & 190 \\
\hline Sand & 30 & 220 \\
\hline Clay & 9 & 229 \\
\hline Sand & 13 & 242 \\
\hline Rock & 6 & 248 \\
\hline Clay & 12 & 260 \\
\hline Sand & 9 & 269 \\
\hline Clay & 26 & 295 \\
\hline Sand & 50 & 345 \\
\hline Clay & 5 & 350 \\
\hline Sand & 32 & 382 \\
\hline $\mathrm{Clay}$ & 8 & 390 \\
\hline Sand & 15 & 405 \\
\hline Sand and rock & 10 & 415 \\
\hline $\mathrm{Clay}$ & 150 & 565 \\
\hline
\end{tabular}

Well TS-60-36-609--Cont inued

Clay and rock $\quad 20 \quad 585$

Clay $\quad 40 \quad 625$

$\begin{array}{lll}\text { Sand } & 20 & 645\end{array}$

Hell TS-60-37-108

Onner: Louis Fritsche, The Fish Pond

Driller: Ma Hater Wells

\begin{tabular}{lcc}
\hline \multicolumn{1}{c}{ Description } & $\begin{array}{c}\text { Thick- } \\
\text { ness } \\
\text { (feet) }\end{array}$ & $\begin{array}{r}\text { Depth } \\
\text { (feet) }\end{array}$ \\
\hline Topsoil, sandy & 4 & 4 \\
Clay, red & 4 & 8 \\
Clay, yell ow and white & 3 & 11 \\
Clay, red and yellow & 11 & 22 \\
Clay and rock; yellow, gray and & 33 & 55 \\
white & 22 & 77 \\
Clay, brown and gray & 66 & 143 \\
Rock and clay; gray and brown & 44 & 187 \\
Clay and rock; gray and brown & 11 & 198 \\
Shale and sand; brown & 77 & 275 \\
Rock and sand; light brown &
\end{tabular}

Well Ts-60-37-412

Omer: City of Willis, Well No. 4

Driller: Layne-Texas Co.

\begin{tabular}{lrc}
\hline \multicolumn{1}{c}{ Description } & $\begin{array}{c}\text { Thick- } \\
\text { ness } \\
\text { (feet) }\end{array}$ & $\begin{array}{c}\text { Depth } \\
\text { (feet) }\end{array}$ \\
\hline Clay and iron ore & 20 & 20 \\
Sand and clay streaks & 12 & 32 \\
Clay & 224 & 256 \\
Shale & 32 & 288 \\
Shale with sand streaks & 5 & 293 \\
Shale & 25 & 318 \\
Shale, sandy & 4 & 322 \\
Shale & 20 & 342 \\
Sand streaks and shale & 10 & 352 \\
Shale & 14 & 366 \\
Sand & 3 & 369 \\
Shale & 21 & 390 \\
Sand streaks and shale & 36 & 426 \\
Shale & 28 & 454 \\
Sand and shale streaks & 41 & 495 \\
Shale & 10 & 505
\end{tabular}


Table 10.--Drillers' loos of wells in Montgomery County--Cont inued

Well Ts-60-37-412--Cont inued

Sand and shale streaks

Lime, hard gravel and shale

Shale

Sand

Shale

Sand

Shale

Shale, sandy with a little gravel

Sand and shale streaks

Shale

Sand and shale streaks

Shale

Sand and shale streaks

Shate

Sand and shale streaks

Shale

Sand and shale streaks

Shate

Sand, shale and lime streaks

Shale

Sand

Sand with a few shale streaks

Shale

Lime, hard with streaks and shale

Shale

Sand and a few streaks of shale

Shale with two small streaks of

sand

Hell TS-60-44-112

Owner: Montgomery Co. M.U.D. No. 3

Driller: O'Day Drilling Co., Inc.

\begin{tabular}{lcc}
\hline Description & $\begin{array}{c}\text { Thick- } \\
\text { ness } \\
\text { (feet) }\end{array}$ & $\begin{array}{c}\text { Depth } \\
\text { (feet) }\end{array}$ \\
\hline Fill & 2 & 2 \\
Sand & 48 & 50 \\
Clay & 115 & 165 \\
Sand & 17 & 182 \\
Clay & 48 & 230 \\
Sand and clay & 76 & 306
\end{tabular}

Well Ts-60-44-112--Cont inued

$\begin{array}{lrc}\text { Clay } & 34 & 340 \\ \text { Sand } & 30 & 370 \\ \text { Clay } & 260 & 630 \\ \text { Sand and clay } & 20 & 650 \\ \text { Sand } & 18 & 668 \\ \text { Sand and clay } & 3 & 671 \\ \text { Sand } & 37 & 708 \\ \text { Sandy clay } & 4 & 712 \\ \text { Sand } & 18 & 730 \\ \text { clay } & 10 & 740\end{array}$

Well is-60-44-113

Owner: Lake Conroe Village

Driller: Weisinger Water Well, Inc.

\begin{tabular}{|c|c|c|}
\hline Description & $\begin{array}{c}\text { Thick- } \\
\text { ness } \\
\text { (feet) }\end{array}$ & $\begin{array}{l}\text { Depth } \\
\text { (feet) }\end{array}$ \\
\hline Sand and clay & 69 & 69 \\
\hline Clay and rock & 23 & 92 \\
\hline Sand and rock & 8 & 100 \\
\hline Sand and clay & 64 & 164 \\
\hline Rock & 1 & 165 \\
\hline Sand and clay & 54 & 219 \\
\hline clay and rock & 2 & 221 \\
\hline Sand and rock & 8 & 229 \\
\hline Clay & 7 & 236 \\
\hline Sand and clay & 18 & 254 \\
\hline Clay & 5 & 259 \\
\hline Sand and clay & 177 & 436 \\
\hline Shale & 10 & 446 \\
\hline clay & 54 & 500 \\
\hline Shale & 28 & 528 \\
\hline Shale & 56 & 584 \\
\hline Shale & 6 & 590 \\
\hline Clay & 34 & 624 \\
\hline Sand & 15 & 639 \\
\hline Rock & 2 & $64 i$ \\
\hline Sand & 41 & 682 \\
\hline Rock & 2 & 684 \\
\hline Shale & 26 & 710 \\
\hline
\end{tabular}


Table 10.--Drillers' logs of wells in Montgomery County--Cont inued

Well TS-60-44-208

Omer: Westmont, Well No. 1

Driller: Weisinger Water Well, Inc.

\begin{tabular}{|c|c|c|}
\hline Description & $\begin{array}{l}\text { Thick- } \\
\text { ness } \\
\text { (feet) }\end{array}$ & $\begin{array}{l}\text { Depth } \\
\text { (feet) }\end{array}$ \\
\hline Clay & 50 & 50 \\
\hline Şand & 32 & 82 \\
\hline Sand and rock & 20 & 102 \\
\hline Rock & 5 & 107 \\
\hline Clay & 25 & 132 \\
\hline Sand & 11 & 143 \\
\hline $\mathrm{Clay}$ and rock & 41 & 184 \\
\hline Clay & 31 & 215 \\
\hline Rock & 1 & 216 \\
\hline Clay & 7 & 223 \\
\hline Clay and rock & 20 & 243 \\
\hline Clay & 47 & 290 \\
\hline Sand & 25 & 315 \\
\hline Clay & 75 & 390 \\
\hline Rock & 3 & 393 \\
\hline Sand & 57 & 450 \\
\hline Clay & 20 & 470 \\
\hline Sand & 50 & 520 \\
\hline
\end{tabular}

Hell TS-60-44-209

Omer: Westmont, Hell No. 2

Driller: Weisinger Water Well, Inc.

\begin{tabular}{lcc}
\hline Description & $\begin{array}{c}\text { Thick- } \\
\text { ness } \\
\text { (feet) }\end{array}$ & $\begin{array}{c}\text { Depth } \\
\text { (feet) }\end{array}$ \\
\hline Clay & 50 & 50 \\
Sand & 35 & 85 \\
Sand and rock & 17 & 102 \\
Rock & 3 & 105 \\
Clay & 28 & 133 \\
Sand & 11 & 144 \\
Clay and rock & 41 & 185 \\
Clay & 40 & 225 \\
Clay and rock & 20 & 245 \\
Clay & 40 & 285 \\
Sand & 30 & 315 \\
Clay & 78 & 393
\end{tabular}

Well TS-60-44-209--Cont inued

Rock

$1 \quad 394$

Sand

56

450

Hell TS-60-44-210

Omer: Haters Edge, Well No. 1

Driller: Weisinger Water Well, Inc.

\begin{tabular}{ccc}
\hline Description & $\begin{array}{c}\text { Thick- } \\
\text { ness } \\
\text { (feet) }\end{array}$ & $\begin{array}{c}\text { Depth } \\
\text { (feet }\end{array}$ \\
\hline
\end{tabular}

clay and rock

55

(feet)

Sand and rock

$17 \quad 72$

Clay

$43 \quad 115$

Sand and rock

$17 \quad 132$

Clay and clay rock streaks

43

175

Sand

14

189

Clay

10

199

Sand

6

205

Clay

49

254

Sand

24

278

Clay

4

282

Sand

291

Clay

296

Sand, broken with clay streaks

332

Clay

352

Sand

396

Clay and shale

440

Sand

480

Clay

500

Sand

Clay

506

Sand and shale

518

Clay

550

Sand

Sand, hard and rock

720

Shale
757

$7 \quad 764$

3 
Table 10.--Drillers' logs of wells in Montgomery County--Cont inued

Well TS-60-44-211

Owner: Waters Edge, Well No. 2

Driller: Weisinger Water Hell, Inc.

\begin{tabular}{|c|c|c|}
\hline Description & $\begin{array}{l}\text { Thick- } \\
\text { ness } \\
\text { (feet) }\end{array}$ & $\begin{array}{l}\text { Depth } \\
\text { (feet) }\end{array}$ \\
\hline $\mathrm{Clay}$ and rock & 55 & 55 \\
\hline Sand and rock & 17 & 72 \\
\hline Clay & 43 & 115 \\
\hline Sand and rock & 17 & 132 \\
\hline Clay and rock streaks & 43 & 175 \\
\hline Sand & 14 & 189 \\
\hline Clay & 10 & 199 \\
\hline Sand & 6 & 205 \\
\hline Clay & 49 & 254 \\
\hline Sand & 24 & 278 \\
\hline Clay & 4 & 282 \\
\hline Sand & 9 & 291 \\
\hline Clay & 5 & 296 \\
\hline Sand, broken with clay streaks & 36 & 332 \\
\hline Clay & 20 & 352 \\
\hline Sand & 44 & 396 \\
\hline clay and shale & 44 & 440 \\
\hline Sand & 40 & 480 \\
\hline
\end{tabular}

Well TS-60-44-212

Owner: Lake Forest Falls

Driller: Coastal Hater Hells, Inc.

\begin{tabular}{lcc}
\hline Description & $\begin{array}{c}\text { Thick- } \\
\text { ness } \\
\text { (feet) }\end{array}$ & $\begin{array}{c}\text { Depth } \\
\text { (feet) }\end{array}$ \\
\hline Sand & 7 & 7 \\
Clay & 53 & 60 \\
Sand & 20 & 80 \\
Clay & 75 & 155 \\
Sand & 25 & 180 \\
Clay and rock & 20 & 200 \\
Sand & 10 & 210 \\
Clay & 55 & 265 \\
Sand & 15 & 280 \\
Clay and rock & 40 & 320 \\
Sand & 25 & 345 \\
Clay and rock & 83 & 428 \\
Sand & 23 & 451
\end{tabular}

Well TS-60-44-212--Cont inued

Clay and shale

7

458

Sand

19

477

Well TS-60-44-312

Owner: Willow Ridge Estates

Driller: Bussell and Son, Inc.

\begin{tabular}{lrc}
\hline Description & $\begin{array}{c}\text { Thick- } \\
\text { ness } \\
\text { (feet) }\end{array}$ & $\begin{array}{c}\text { Depth } \\
\text { (feet) }\end{array}$ \\
\hline Sand & 4 & 4 \\
Clay & 13 & 17 \\
Sand & 18 & 35 \\
Clay & 85 & 120 \\
Sand & 8 & 128 \\
Clay & 7 & 135 \\
Rock and silt streaks & 32 & 167 \\
Sand & 23 & 190 \\
Clay, sandy & 103 & 293 \\
Sand & 17 & 310 \\
Clay, tough & 38 & 348 \\
Sand & 30 & 378 \\
Clay & 8 & 386 \\
Sand & 44 & 430
\end{tabular}

Well TS-60-44-313

Owner: Wedgewood Golf Course, Well No. 1

Driller: Heisinger Water Hell, Inc.

\begin{tabular}{lcc}
\hline Description & $\begin{array}{c}\text { Thick- } \\
\text { ness } \\
\text { (feet) }\end{array}$ & $\begin{array}{c}\text { Depth } \\
\text { (feet) }\end{array}$ \\
\hline Sand & 22 & 22 \\
Clay & 28 & 50 \\
Sand & 25 & 75 \\
Clay & 65 & 140 \\
Rock & 65 & 145 \\
Clay & 5 & 175 \\
Rock & 30 & 176 \\
Clay & 1 & 190 \\
Rock & 14 & 192 \\
Clay & 2 & 240 \\
Rock & 48 & 243 \\
Clay & 3 & 304 \\
Rock & 61 & 306
\end{tabular}


Table 10.--Drillers' loos of wells in Montocmery County--Cont inued

Well TS-60-44-313--Cont inued

$\begin{array}{lrr}\text { Clay } & 14 & 320 \\ \text { Rock } & 3 & 323 \\ \text { Sand and rock } & 13 & 336 \\ \text { Clay } & 44 & 380 \\ \text { Sand } & 30 & 410 \\ \text { Clay } & 6 & 416 \\ \text { Sand and rock } & 24 & 440 \\ \text { Clay } & 40 & 480 \\ \text { Sand } & 40 & 520 \\ \text { Clay } & 50 & 570 \\ \text { Rock } & 2 & 572 \\ \text { Sand } & 24 & 596 \\ \text { Clay } & 38 & 634 \\ \text { Sand } & 26 & 660\end{array}$

Well Ts-60-44-314

Owner: Wedgewood Golf Course, Well No. 2

Driller: Weisinger Water Well, Inc.

\begin{tabular}{|c|c|c|}
\hline Description & $\begin{array}{l}\text { Thick- } \\
\text { ness } \\
\text { (feet) }\end{array}$ & $\begin{array}{l}\text { Depth } \\
\text { (feet) }\end{array}$ \\
\hline Sand & 22 & 22 \\
\hline Clay & 28 & 50 \\
\hline Sand & 25 & 75 \\
\hline Clay & 65 & 140 \\
\hline Rock & 5 & 145 \\
\hline Clay & 30 & 175 \\
\hline Rock & 1 & 176 \\
\hline Clay & 14 & 190 \\
\hline Rock & 2 & 192 \\
\hline Clay & 48 & 240 \\
\hline Rock & 3 & 243 \\
\hline clay & 61 & 304 \\
\hline Rock & 2 & 306 \\
\hline Clay & 14 & 320 \\
\hline Rock & 3 & 323 \\
\hline Sand and rock & 13 & 336 \\
\hline Clay & 44 & 380 \\
\hline Sand & 30 & 410 \\
\hline Clay & 6 & 416 \\
\hline Sand and rock & 24 & 440 \\
\hline
\end{tabular}

Well TS-60-44-314--Cont inued

$\begin{array}{lcc}\text { Clay } & 40 & 480 \\ \text { Sand } & 40 & 520 \\ \text { Clay } & 50 & 570 \\ \text { Rock } & 2 & 572 \\ \text { Sand } & 24 & 596 \\ \text { Clay } & 38 & 634 \\ \text { Sand } & 38 & 660\end{array}$

Well TS-60-45-113

Owner: Dailey Oil Tool

Driller: Weisinger Water Well, Inc.

\begin{tabular}{|c|c|c|}
\hline Description & $\begin{array}{l}\text { Thick- } \\
\text { ness } \\
\text { (feet) }\end{array}$ & $\begin{array}{l}\text { Depth } \\
\text { (feet) }\end{array}$ \\
\hline Clay & 30 & 30 \\
\hline Sand & 15 & 45 \\
\hline Clay & 33 & 78 \\
\hline Sand & 42 & 120 \\
\hline Clay & 20 & 140 \\
\hline Sand & 12 & 152 \\
\hline Clay & 33 & 185 \\
\hline Clay and rock & 20 & 205 \\
\hline $\mathrm{Clay}$ & 20 & 225 \\
\hline Rock & 2 & 227 \\
\hline Clay & 17 & 244 \\
\hline Clay and rock & 21 & 265 \\
\hline Clay & 35 & 300 \\
\hline Rock & 3 & 303 \\
\hline Clay & 19 & 322 \\
\hline Rock & 2 & 324 \\
\hline Clay & 11 & 335 \\
\hline Rock & 1 & 336 \\
\hline Clay & 47 & 383 \\
\hline Rock & 3 & 386 \\
\hline Clay & 12 & 398 \\
\hline Rock & 2 & 400 \\
\hline Clay & 15 & 415 \\
\hline Rock & 1 & 416 \\
\hline Clay & 51 & 467 \\
\hline Rock & 2 & 469 \\
\hline
\end{tabular}


Table 10.--Drillers' logs of wells in Montgomery Canty--Cont inued

Well TS-60-45-113--Cont inued

Clay

11

60

480

Sand

Hell TS-60-45-114

Owner: Gilmore's Florist and Nursery, Inc.

Driller: Heisinger Water Hell, Inc.

\begin{tabular}{lrc}
\hline Description & $\begin{array}{c}\text { Thick- } \\
\text { ness } \\
\text { (feet) }\end{array}$ & $\begin{array}{c}\text { Depth } \\
\text { (feet) }\end{array}$ \\
\hline Clay & 24 & 24 \\
Sand & 6 & 30 \\
Clay & 24 & 54 \\
Sand & 74 & 128
\end{tabular}

Well TS-60-45-207

Ouner: City of Conroe, Well No. 13

Driller: Layne-Texas Co.

\begin{tabular}{|c|c|c|}
\hline Description & $\begin{array}{l}\text { Thick- } \\
\text { ness } \\
\text { (feet) }\end{array}$ & $\begin{array}{l}\text { Depth } \\
\text { (feet) }\end{array}$ \\
\hline Topsoil clay & 20 & 20 \\
\hline Sand & 23 & 43 \\
\hline Clay & 19 & 62 \\
\hline Sand & 31 & 93 \\
\hline clay & 10 & 103 \\
\hline Sand & 32 & 135 \\
\hline clay & 135 & 270 \\
\hline Clay with lime and sand streaks & 30 & 300 \\
\hline Clay & 187 & 487 \\
\hline Sand and shale & 11 & 498 \\
\hline Clay & 72 & 570 \\
\hline Sand & 29 & 599 \\
\hline Sand and shale & 13 & 612 \\
\hline Shale & 7 & 619 \\
\hline Sand and shale layers & 39 & 658 \\
\hline Shale & 172 & 830 \\
\hline Sand, fine & 20 & 850 \\
\hline Shale & 15 & 865 \\
\hline Sand & 36 & 901 \\
\hline Shale and hard, broken sand & 23 & 924 \\
\hline Sand and shale layers & 13 & 937 \\
\hline Shale & 12 & 949 \\
\hline Sand and shale layers & 86 & 1,035 \\
\hline
\end{tabular}

Well TS $-60-45-207--$ Continued

Sand and broken shale 18

1,053

Shale

13

1,066

Sand, shale and hard streaks

26

1,092

Shale and hard streaks

1,123

Sand

31

1,143

Shale

20

1,247

shale and lime

Shale and hard streaks

$37 \quad 1,284$

$66 \quad 1,350$

Hell TS-60-45-208

Owner: City of Conroe, Hell No. 12

Driller: Layne-Texas Co.

\begin{tabular}{|c|c|c|}
\hline Description & $\begin{array}{l}\text { Thick- } \\
\text { ness } \\
\text { (feet) }\end{array}$ & $\begin{array}{l}\text { Depth } \\
\text { (feet) }\end{array}$ \\
\hline Topsoil & 1 & 1 \\
\hline Clay & 10 & 11 \\
\hline Clay and sandy clay streaks & 5 & 16 \\
\hline Clay & 21 & 37 \\
\hline Sand & 24 & 61 \\
\hline $\mathrm{Clay}$ and sand & 2 & 63 \\
\hline Sand and clay streaks & 2 & 65 \\
\hline Sand & 2 & 67 \\
\hline Sand and gravel & 15 & 82 \\
\hline Rock and clay streaks & 7 & 89 \\
\hline Clay & 6 & 95 \\
\hline Sand & 16 & 111 \\
\hline Sand, gravel and clay streaks & 33 & 144 \\
\hline Gravel and sand & 10 & 154 \\
\hline Gravel, sand and clay streaks & 25 & 179 \\
\hline Clay and rock & 3 & 182 \\
\hline Clay and sandy clay & 12 & 194 \\
\hline Sandy clay and sand streaks & 6 & 200 \\
\hline Clay and sandy clay & 7 & 207 \\
\hline Shale and lime streaks & 1 & 208 \\
\hline Shale and clay streaks & 17 & 225 \\
\hline $\mathrm{Clay}$ and sandy clay & 15 & 240 \\
\hline Clay, shale and lime streaks & 15 & 255 \\
\hline $\mathrm{Clay}$ and sandy clay & 10 & 265 \\
\hline Clay & 6 & 271 \\
\hline Clay and sandy clay streaks & 17 & 288 \\
\hline
\end{tabular}


Table 10.--Drillers' logs of wells in Montgomery County--Cont inued

Well TS-60-45-208--Cont inued

Lime

clay

Lime

Clay and lime streaks

Clay and sandy clay streaks

Clay and sand streaks

Clay and sandy clay streaks

Sand

Clay

Clay and sandy clay streaks

Clay

Clay and shale streaks

Clay, sandy clay and shale streaks

Sand and clay

Clay and shale

Sand and clay streaks

Clay, shale and sand streaks

Sand and clay streaks

Clay and sand streaks

Clay and shale

Shale and sandy shale streaks

Clay and sandy clay

Clay, lime and sand streaks

Shale and lime streaks

Shale

Shale, sand and lime streaks

Shale and clay streaks

Shale and a few sand streaks

Shale, clay and lime streaks

Shale

Clay and shale

Clay and sandy clay streaks

Send and clay streaks

clay

Sand and clay streaks

Clay, sandy clay and sand streaks

Sand

clay

1289

$55 \quad 344$

\section{1}

345

36

6
Hell TS-60-45-208--Cont inued

Sand and clay streaks 11

868

Lime

869

Sand and clay

872

Clay and lime streaks $\quad 8 \quad 880$

Shale, lime streaks and clay $\quad 15 \quad 895$

Clay and sandy clay $\quad 2 \quad 897$

Sand and clay streaks $\quad 9906$

Sand $\quad 5 \quad 911$

Clay $\quad 25 \quad 936$

Sand and clay streaks $\quad 30 \quad 966$

Lime streaks, sand and clay streaks $34 \quad 1,000$

Clay and sandy clay $3 \quad 1,003$

$\begin{array}{lll}\text { Lime streaks and sand } & 16 & 1,019\end{array}$

$\begin{array}{lll}\text { Lime and clay streaks } & 2 & 1,021\end{array}$

Lime and sand $\quad 2 \quad 1,023$

$\begin{array}{lll}\text { Lime } & 1 & 1,024\end{array}$

$\begin{array}{lll}\text { Sand } & 3 & 1,027\end{array}$

$\begin{array}{lll}\text { Lime streaks and sand } & 9 & 1,036\end{array}$

clay, lime streaks and shale $\quad 8 \quad 1,044$

Clay, shale and lime $\quad 21 \quad 1,065$

$\begin{array}{lll}\text { Clay, sand and shale } & 19 & 1,084\end{array}$

Clay, shale and a few sand streaks $\quad 40 \quad 1,124$

$\begin{array}{lll}\text { Clay and sand } & 16 & 1,140\end{array}$

Clay, shale and a few sand streaks $25 \quad 1,165$

$\begin{array}{llll}\text { Shale and clay streaks } & 10 & 1,175\end{array}$

$\begin{array}{lll}\text { Shale and a few sand streaks } & 5 & 1,180\end{array}$

$\begin{array}{lll}\text { Clay and shale } & 7 & 1,187\end{array}$

Sand and clay streaks $\quad 9 \quad 1,196$

Clay, sandy clay and lime $3 \quad 1,199$

Sand, shale and clay streaks $\quad 27 \quad 1,226$

Shale, clay and lime streaks $\quad 29 \quad 1,255$

$\begin{array}{lll}\text { Clay and sand streaks } & 4 & 1,259\end{array}$

Lime $\quad 2 \quad 1,261$

Sand, clay and lime streaks $\quad 7 \quad 1,268$

Lime $\quad 2 \quad 1,270$

Sand, clay and lime streaks $\quad 31 \quad 1,301$

Lime 1,302

Shale and clay $\quad 2 \quad 1,304$ 
Table 10.--Drillers' logs of wells in Montgomery County--Cont inued

Hell TS-60-45-208--Cont inued

$\begin{array}{lrr}\text { Sand and clay streaks } & 5 & 1,309 \\ \text { Shale and a few sand streaks } & 7 & 1,316 \\ \text { Lime } & 1 & 1,317 \\ \text { Shale and clay streaks } & 28 & 1,345 \\ \text { Shale and lime streaks } & 5 & 1,350\end{array}$

Well TS-60-45-304

Omer: Western Waste Industry of Texas

Driller: Custom Coring, Inc.

\begin{tabular}{lcc}
\hline Description & $\begin{array}{c}\text { Thick- } \\
\text { ness } \\
\text { (feet) }\end{array}$ & $\begin{array}{c}\text { Depth } \\
\text { (feet) }\end{array}$ \\
\hline
\end{tabular}

$\begin{array}{lrr}\text { Clayey silt, brown } & 3 & 3 \\ \text { Sandy clay, tan and gray } & 9 & 12 \\ \text { Clay, light gray } & 22 & 34 \\ \text { Clay, red-brown } & 34 & 68 \\ \text { Silty clay, red-brown } & 14 & 82 \\ \text { Sand, medium to coarse, brown with } & 5 & 87 \\ \text { clay layers } & 5 & 98 \\ \text { Sand, fine, brown } & 11 & \end{array}$

Hell TS-60-45-412

Ouner: Harris-Galveston Coastal Subsidence District, Conroe Well No. 1

Driller: Texas Water Development Board

\begin{tabular}{|c|c|c|}
\hline Description & $\begin{array}{c}\text { Thick- } \\
\text { ness } \\
\text { (feet) }\end{array}$ & $\begin{array}{l}\text { Depth } \\
\text { (feet) }\end{array}$ \\
\hline Topsoil & 3 & 3 \\
\hline Clay, red & 2 & 5 \\
\hline Sand, red & 3 & 8 \\
\hline Sand, tan & 8 & 16 \\
\hline Sand and clay & 9 & 25 \\
\hline Clay and sand & 7 & 32 \\
\hline Clay, tan & 33 & 65 \\
\hline Sand, tan & 13 & 78 \\
\hline Sand, coarse & 10 & 88 \\
\hline Coarse sand and pea gravel & 31 & 119 \\
\hline Gravel, pea & 4 & 123 \\
\hline Sand, fine & 6 & 129 \\
\hline Sand and clay & 6 & 135 \\
\hline Clay and some sand & 60 & 195 \\
\hline Clay & 22 & 217 \\
\hline Sand and some clay & 53 & 270 \\
\hline
\end{tabular}

Well TS-60-45-513

Ouner: Weisinger Water Well, Inc.

Driller: Weisinger Water Hell Inc.

\begin{tabular}{lcc}
\hline Description & $\begin{array}{c}\text { Thick- } \\
\text { ness } \\
\text { (feet) }\end{array}$ & $\begin{array}{c}\text { Depth } \\
\text { (feet) }\end{array}$ \\
\hline Clay & 85 & 85 \\
Sand & 40 & 125 \\
Clay & 25 & 150 \\
Sand & 18 & 168
\end{tabular}

Well TS-60-45-613

Oner: Crystal Creek Grocery

Driller: Weisinger Water Well, Inc.

\begin{tabular}{|c|c|c|}
\hline Description & $\begin{array}{l}\text { Thick- } \\
\text { ness } \\
\text { (feet) }\end{array}$ & $\begin{array}{l}\text { Depth } \\
\text { (feet) }\end{array}$ \\
\hline Sand & 25 & 25 \\
\hline Clay & 22 & 47 \\
\hline Rock and clay & 7 & 54 \\
\hline Clay & 16 & 70 \\
\hline Rock & 2 & 72 \\
\hline Clay & 68 & 140 \\
\hline Rock & 1 & 141 \\
\hline Clay & 8 & 149 \\
\hline Rock & 1 & 150 \\
\hline Clay & 10 & 160 \\
\hline Rock & 1 & 161 \\
\hline Clay & 9 & 170 \\
\hline Rock & 1 & 171 \\
\hline Clay & 34 & 205 \\
\hline Rock & 1 & 206 \\
\hline Clay & 9 & 215 \\
\hline Rock & 1 & 216 \\
\hline Clay & 20 & 236 \\
\hline Sand & 14 & 250 \\
\hline \multicolumn{3}{|c|}{$\begin{array}{l}\text { Well is }-60-45-714 \\
\text { aner: City of Conroe, Sewage Plant } \\
\text { Driller: Weisinger Water Well, Inc. }\end{array}$} \\
\hline Description & $\begin{array}{l}\text { Thick- } \\
\text { ness } \\
\text { (feet) }\end{array}$ & $\begin{array}{l}\text { Depth } \\
\text { (feet) }\end{array}$ \\
\hline Sand & 60 & 60 \\
\hline Clay & 15 & $\pi$ \\
\hline Sand & 13 & 88 \\
\hline
\end{tabular}


Table 10.--Drillers' logs of wells in Montgomery County--Cont inued

Well TS-60-45-714--Cont inued

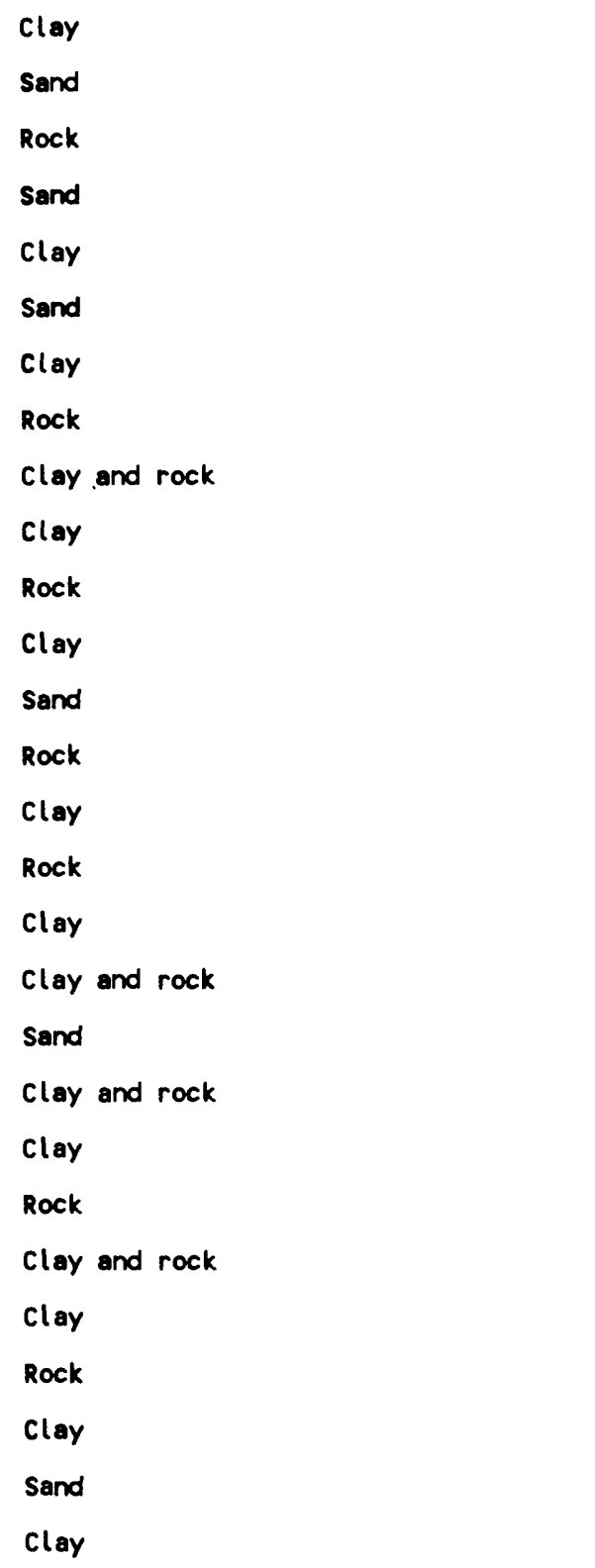

Well TS-60-50-305--Cont inved

\begin{tabular}{|c|c|}
\hline Sand & 8 \\
\hline Rock & 10 \\
\hline Rock and sand, mixed & 6 \\
\hline Sand & 2 \\
\hline Rock & 6 \\
\hline Sand & 20 \\
\hline Sand and clay, mixed & 2 \\
\hline Sand & 18 \\
\hline Clay & 47 \\
\hline Sand & 8 \\
\hline clay & 109 \\
\hline Rock & 1 \\
\hline Clay & 17 \\
\hline Rock & 1 \\
\hline Clay & 4 \\
\hline Sand & 3 \\
\hline Rock & 2 \\
\hline Clay & 30 \\
\hline Rock & 1 \\
\hline Clay & 39 \\
\hline Rock & 1 \\
\hline Clay & 14 \\
\hline Sand & 29 \\
\hline Clay & 16 \\
\hline Sand & 44 \\
\hline Sand and clay & 12 \\
\hline Sand & 26 \\
\hline
\end{tabular}

Well TS-60-50-610

Owner: Woodlands Lakes Civic Club, South Well

Driller: Weisinger Water Hell, Inc.

\begin{tabular}{lcc}
\hline Description & $\begin{array}{c}\text { Thick- } \\
\text { ness } \\
\text { (feet) }\end{array}$ & $\begin{array}{c}\text { Depth } \\
\text { (feet) }\end{array}$ \\
\hline Clay & 45 & 45 \\
Sand & 15 & 60 \\
Clay & 100 & 160 \\
Sand & 20 & 180 \\
Clay & 20 & 200 \\
Sand & 4 & 204 \\
Sand and rock & 8 & 212
\end{tabular}


Table 10.--Drillers' logs of wells in Montgomery County--Cont inued

Hell TS-60-50-610--Continued

$\begin{array}{lcc}\text { Clay } & 18 & 230 \\ \text { Rock } & 5 & 235 \\ \text { Sand } & 8 & 243 \\ \text { Rock } & 2 & 245 \\ \text { Sand } & 12 & 257 \\ \text { Clay } & 16 & 273 \\ \text { Sand } & 32 & 305\end{array}$

Hell TS-60-50-611

Owner: Clover Creek

Driller: Bussell and Son, Inc.

\begin{tabular}{lcc}
\hline \multicolumn{1}{c}{ Description } & $\begin{array}{c}\text { Thick- } \\
\text { ness } \\
\text { (feet) }\end{array}$ & $\begin{array}{c}\text { Depth } \\
\text { (feet) }\end{array}$ \\
\hline Topsoil and clay & 67 & 67 \\
Surface sand & 33 & 100 \\
Clay & 7 & 107 \\
Sand & 8 & 115 \\
Clay, sandy & 9 & 124 \\
Sand & 43 & 167 \\
Clay & 97 & 264 \\
Rock, hard and sand streaks & 2 & 266 \\
Rock & 1 & 267 \\
Sand & 6 & 273 \\
Clay & 12 & 285 \\
Claystone, broken & 11 & 296 \\
Sand & 42 & 338
\end{tabular}

Hell TS-60-59-104

Owner: Southwest Utilities

Driller: Raymond Water Wells

\begin{tabular}{lcc}
\hline Description & $\begin{array}{c}\text { Thick- } \\
\text { ness } \\
\text { (feet) }\end{array}$ & $\begin{array}{c}\text { Depth } \\
\text { (feet) }\end{array}$ \\
\hline Iron ore, red & 20 & 20 \\
Iron ore clay & 20 & 40 \\
Clay and sand & 20 & 60 \\
Clay and sand & 20 & 80 \\
Sand & 20 & 100 \\
Sand and clay & 20 & 120 \\
Sand & 20 & 140 \\
Sand and clay & 20 & 160 \\
Clay & 20 & 180
\end{tabular}

Well TS-60-51-104--Cont inued

$\begin{array}{lcc}\text { Clay, sand and sand streaks } & 20 & 200 \\ \text { Clay, sand and sand streaks } & 20 & 220 \\ \text { Sand, clay and sand streaks } & 20 & 240 \\ \text { Sand and iron ore } & 20 & 260 \\ \text { Sand } & 20 & 280 \\ \text { Sand } & 20 & 300 \\ \text { Sand } & 10 & 310 \\ \text { Sand } & 10 & 320 \\ \text { Sand } & 8 & 328 \\ \text { Rock } & 7 & 335 \\ \text { Sand } & 5 & 340\end{array}$

Well TS-60-51-513

Owner: Northwest Water System, Hazy Hollow Hell No. 1-A Driller: Waller County water Wells

\begin{tabular}{|c|c|c|}
\hline Description & $\begin{array}{l}\text { Thick- } \\
\text { ness } \\
\text { (feet) }\end{array}$ & $\begin{array}{l}\text { Depth } \\
\text { (feet) }\end{array}$ \\
\hline Clay, red & 26 & 26 \\
\hline Sand, red & 23 & 49 \\
\hline clay, brown & 5 & 54 \\
\hline Sand, red & 17 & 71 \\
\hline clay, brown, sticky & 62 & 133 \\
\hline Sand, white & 27 & 160 \\
\hline clay, brown & 3 & 163 \\
\hline Sand, coarse, white & 64 & 227 \\
\hline Clay, white & 18 & 245 \\
\hline Sand, white & 7 & 252 \\
\hline Clay, purple & 75 & 327 \\
\hline Limestone & 3 & 330 \\
\hline Shale & 53 & 383 \\
\hline Sand, brown and rock & 32 & 495 \\
\hline \multicolumn{3}{|c|}{$\begin{array}{l}\text { Well TS-60-51-603 } \\
\text { Owner: Silver Spring Baptist Church } \\
\text { Oriller: Tri-County Water Wells }\end{array}$} \\
\hline Description & $\begin{array}{l}\text { Thick- } \\
\text { ness } \\
\text { (feet) }\end{array}$ & $\begin{array}{l}\text { Depth } \\
\text { (feet) }\end{array}$ \\
\hline Clay, red & 60 & 60 \\
\hline Sand & 68 & 128 \\
\hline Clay & 24 & 152 \\
\hline Sand & 79 & 231 \\
\hline
\end{tabular}


Well TS-60-51-603--Cont inued

$\begin{array}{lrr}\text { Clay } & 9 & 240 \\ \text { Sand } & 46 & 286\end{array}$

Well TS-60-51-704

Owner: Blue Bell Manor Utilities, Dog Wood Hills

Driller: B.J. Swinehert, Co.

\begin{tabular}{|c|c|c|}
\hline Description & $\begin{array}{l}\text { Thick- } \\
\text { ness } \\
\text { (feet) }\end{array}$ & $\begin{array}{l}\text { Depth } \\
\text { (feet) }\end{array}$ \\
\hline Surface & 3 & 3 \\
\hline Clay & 92 & 95 \\
\hline Sand & 28 & 123 \\
\hline Clay & 6 & 129 \\
\hline Sand & 43 & 172 \\
\hline Clay and sand streaks & 51 & 223 \\
\hline Sand & 38 & 261 \\
\hline Clay & 16 & 277 \\
\hline Sand & 75 & 352 \\
\hline Unrecorded & 1 & 353 \\
\hline \multicolumn{3}{|c|}{$\begin{array}{l}\text { Well TS-60-52-107 } \\
\text { Owner: Cimarron Way } \\
\text { Oriller: Coastal Water Wells, Inc. }\end{array}$} \\
\hline Description & $\begin{array}{l}\text { Thick- } \\
\text { ness } \\
\text { (feet) }\end{array}$ & $\begin{array}{l}\text { Depth } \\
\text { (feet) }\end{array}$ \\
\hline Surface sand & 10 & 10 \\
\hline Clay & 62 & 72 \\
\hline Sand and gravel & 18 & 90 \\
\hline Clay & 75 & 165 \\
\hline Sand and rock streaks & 26 & 191 \\
\hline Clay & 69 & 260 \\
\hline Sand & 30 & 290 \\
\hline Clay & 55 & 345 \\
\hline Sand & 9 & 354 \\
\hline Rock & 11 & 365 \\
\hline Clay & 55 & 420 \\
\hline Sand and rock & 8 & 428 \\
\hline clay & 122 & 550 \\
\hline
\end{tabular}

Well TS-60-52-603

Owner: The Woodlands Corp., Well No. 6

Driller: Layne-Western Co., Inc.

\begin{tabular}{|c|c|c|}
\hline Description & $\begin{array}{l}\text { Thick- } \\
\text { ness } \\
\text { (feet) }\end{array}$ & $\begin{array}{l}\text { Depth } \\
\text { (feet) }\end{array}$ \\
\hline Unrecorded & 40 & 40 \\
\hline Clay & 40 & 80 \\
\hline Gravel and sand & 20 & 100 \\
\hline Clay, sticky & 12 & 112 \\
\hline Sand & 28 & 140 \\
\hline $\mathrm{Clay}$ and sand & 10 & 150 \\
\hline Clay & 30 & 180 \\
\hline Sand and clay & 35 & 215 \\
\hline Clay & 3 & 218 \\
\hline Sand & 7 & 225 \\
\hline Clay & 5 & 230 \\
\hline Sand & 24 & 254 \\
\hline Clay & 3 & 257 \\
\hline Send & 93 & 350 \\
\hline Clay & 35 & 385 \\
\hline Sand and clay & 10 & 395 \\
\hline Clay & 93 & 488 \\
\hline Sand and clay & 3 & 491 \\
\hline Rock, hard & 1 & 492 \\
\hline Sand and clay & 9 & 501 \\
\hline Clay & 63 & 564 \\
\hline Clay with sand & 21 & 585 \\
\hline Clay & 111 & 696 \\
\hline Sand and shale & 34 & 730 \\
\hline Shale & 30 & 760 \\
\hline Shale and sand & 15 & $\pi / 5$ \\
\hline Shale & 15 & 790 \\
\hline Sand & 10 & 800 \\
\hline Shale & 64 & 864 \\
\hline Sand with shale streaks & 16 & 880 \\
\hline Shale & 56 & 936 \\
\hline Sand & 9 & 945 \\
\hline Shale & 24 & 969 \\
\hline Sand & 21 & 990 \\
\hline Sand and shale & 10 & 1,000 \\
\hline
\end{tabular}


Table 10.--Drillers' logs of wells in Montgomery County--Cont inued

Well TS-60-52-603--Continued

Shale

Unrecorded

- 1,000

51,005

Well TS-60-53-210

Omer: Bison Building Material, Inc.

Driller: Heisinger Water Hell, Inc.

\begin{tabular}{lcc}
\hline Description & $\begin{array}{c}\text { Thick- } \\
\text { ness } \\
\text { (feet) }\end{array}$ & $\begin{array}{c}\text { Depth } \\
\text { (feet) }\end{array}$ \\
\hline Sand & 110 & 110 \\
Clay & 26 & 136 \\
Sand and rock & 26 & 162 \\
Clay & 18 & 180 \\
Rock & 3 & 183 \\
Sand and rock & 20 & 203 \\
Sand & 19 & 222
\end{tabular}

Well TS-60-53-514

Owner: City of Shenandoah, Hell No. 2

Driller: Lanford Drilling Co., Inc.

\begin{tabular}{|c|c|c|}
\hline Description & $\begin{array}{c}\text { Thick- } \\
\text { ness } \\
\text { (feet) }\end{array}$ & $\begin{array}{l}\text { Depth } \\
\text { (feet) }\end{array}$ \\
\hline Surface & 3 & 3 \\
\hline Clay & 8 & 11 \\
\hline Sand and gravel & 34 & 45 \\
\hline Clay & 13 & 58 \\
\hline Sand and gravel & 61 & 119 \\
\hline Shale, sandy & 46 & 165 \\
\hline Sand & 40 & 205 \\
\hline Shale & 15 & 220 \\
\hline Sand with shale streaks & 85 & 305 \\
\hline Shale & 27 & 332 \\
\hline Sand & 33 & 365 \\
\hline Shale & 40 & 405 \\
\hline Shale, sandy & 25 & 430 \\
\hline Sand & 60 & 490 \\
\hline Shale & 160 & 650 \\
\hline Sand & 18 & 668 \\
\hline Shale and sandy shale & 57 & 725 \\
\hline Sand & 130 & 855 \\
\hline Shale & 25 & 880 \\
\hline Sand & 45 & 925 \\
\hline
\end{tabular}

Well TS-60-53-514--Cont inued

$\begin{array}{lrr}\text { Shale } & 35 & 960 \\ \text { Sand } & 10 & 970 \\ \text { Shale and sandy shale streaks } & 245 & 1,215 \\ \text { Sand and sandy shale } & 55 & 1,270 \\ \text { Shale, sandy } & 47 & 1,317\end{array}$

Well TS-60-53-515

Ower: Conroe Independent School District, Oakridge North Junior High

Driller: Weisinger Water Well, Inc.

\begin{tabular}{lcc}
\hline Description & $\begin{array}{c}\text { Thick- } \\
\text { ness } \\
\text { (feet) }\end{array}$ & $\begin{array}{c}\text { Depth } \\
\text { (feet) }\end{array}$ \\
\hline Clay & 38 & 38 \\
Sand & 42 & 80 \\
Clay & 15 & 95 \\
Sand & 15 & 110 \\
Clay & 68 & 178 \\
Sand & 42 & 220 \\
Clay & 46 & 266 \\
Sand & 39 & 305 \\
Clay and rock & 25 & 330 \\
Sand & 35 & 365 \\
Clay and rock & 70 & 435 \\
Sand & 90 & 525 \\
Clay & 15 & 540
\end{tabular}

Well TS-60-53-822

Owner: J.C. Egan

Driller: Weisinger Water Well, Inc.

\begin{tabular}{lcc}
\hline Description & $\begin{array}{c}\text { Thick- } \\
\text { ness } \\
\text { (feet) }\end{array}$ & $\begin{array}{c}\text { Depth } \\
\text { (feet) }\end{array}$ \\
\hline Clay & 20 & 20 \\
Sand & 95 & 115 \\
Rock & 20 & 135 \\
Rock & 1 & 136 \\
Clay & 7 & 143 \\
Rock & 5 & 148 \\
Clay & 47 & 195 \\
Rock & 1 & 196 \\
Sand & 14 & 210 \\
Clay & 10 & 220 \\
Sand & 10 & 230
\end{tabular}


Table 10.--Drillers' logs of wells in Montgomery County--Cont inued

Well TS-60-53-822--Cont inued

$\begin{array}{lcc}\text { Clay } & 15 & 245 \\ \text { Clay and rock } & 11 & 256 \\ \text { Sand } & 34 & 290 \\ \text { Rock } & 3 & 293 \\ \text { Clay } & 15 & 308 \\ \text { Sand } & 22 & 330 \\ \text { Clay } & 15 & 345 \\ \text { Sand } & 25 & 370\end{array}$

Well TS-60-54-306

Owner: Crystal Springs Water Co., Whispering Pines, Well No. 2

Driller: Lowe Water Wells, Inc.

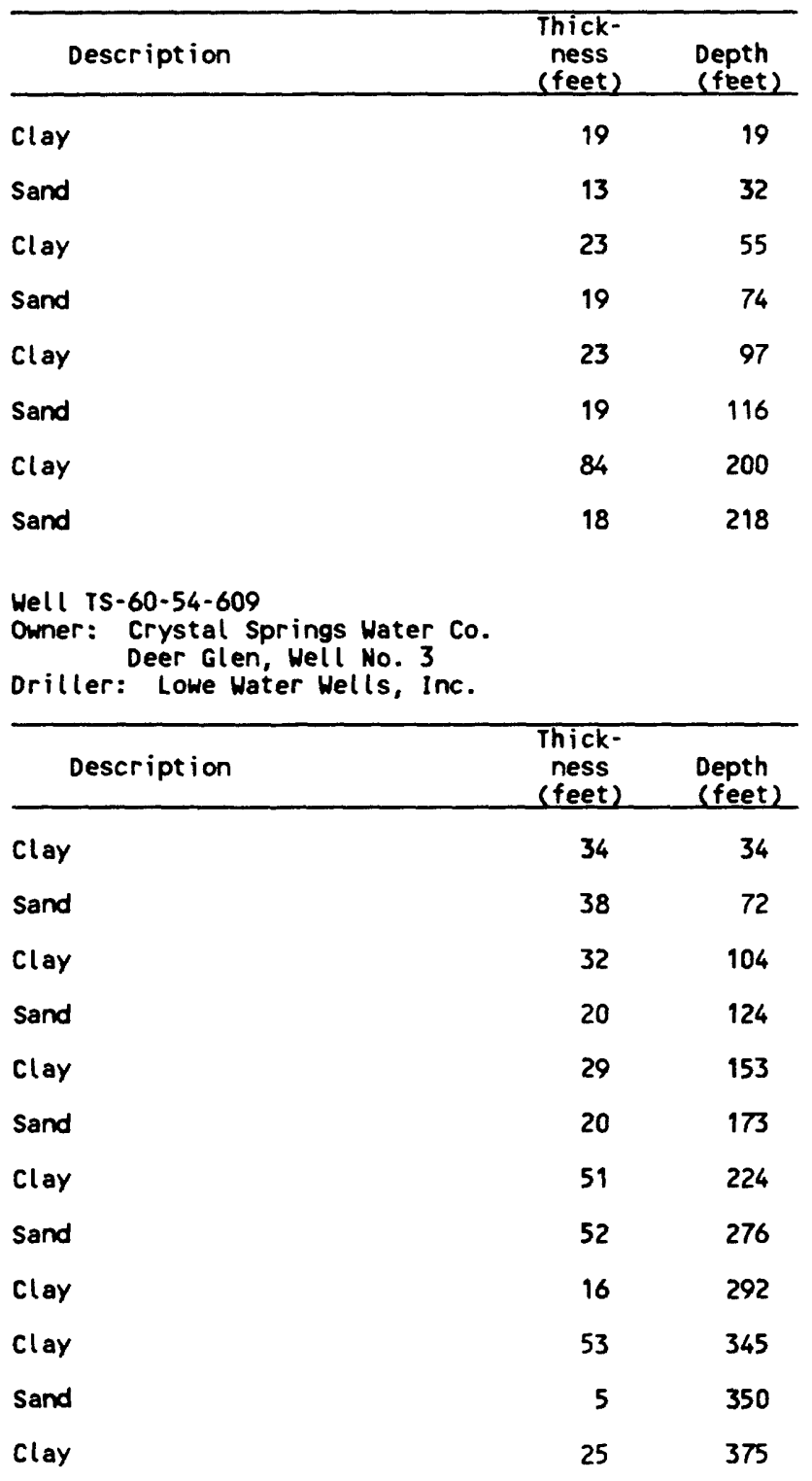

Well TS-60-54-609--Cont inued

Sand $\quad 9 \quad 384$

Sand $\quad 18 \quad 402$

Clay $\quad 3 \quad 405$

Well Ts-60-54-906

Owner: Crystal Springs Water Co.

Driller: Lowe Water Wells, Inc.

\begin{tabular}{|c|c|c|}
\hline Description & $\begin{array}{c}\text { Thick- } \\
\text { ness } \\
\text { (feet) }\end{array}$ & $\begin{array}{l}\text { Depth } \\
\text { (feet) }\end{array}$ \\
\hline $\mathrm{Clay}$ & 51 & 51 \\
\hline Sand & 21 & 72 \\
\hline $\mathrm{Clay}$ & 16 & 88 \\
\hline Sand & 36 & 124 \\
\hline Clay & 24 & 148 \\
\hline Sand & 24 & 172 \\
\hline Clay & 16 & 188 \\
\hline Sand & 57 & 245 \\
\hline Clay & 132 & 377 \\
\hline Sand & 26 & 403 \\
\hline Clay & 2 & 405 \\
\hline \multicolumn{3}{|c|}{$\begin{array}{l}\text { Well TS- } 60-55-708 \\
\text { Owner: New Caney M.U.D., Hell No. } 1 \\
\text { Driller: Lanford Drilling Co., Inc. }\end{array}$} \\
\hline Description & $\begin{array}{c}\text { Thick- } \\
\text { ness } \\
\text { (feet) }\end{array}$ & $\begin{array}{l}\text { Depth } \\
\text { (feet) }\end{array}$ \\
\hline Surface & 3 & 3 \\
\hline Clay & 5 & 8 \\
\hline Gravel and sand & 17 & 25 \\
\hline Shale & 8 & 33 \\
\hline Shale, sandy & 12 & 45 \\
\hline Gravel & 55 & 100 \\
\hline Gravel and sand & 19 & 119 \\
\hline Shale, sandy & 16 & 135 \\
\hline Sand with shale streaks & 85 & 220 \\
\hline Shale & 22 & 242 \\
\hline Sand & 13 & 255 \\
\hline Shale & 15 & 270 \\
\hline Shale, sandy & 10 & 280 \\
\hline Shale & 32 & 312 \\
\hline Sand & 88 & 400 \\
\hline
\end{tabular}


Table 10.--Drillers' logs of wells in Montgomery County--Cont inued

Well TS-60-55-708--Cont inued

$\begin{array}{lrr}\text { Shale } & 40 & 440 \\ \text { Sand } & 12 & 452 \\ \text { Shale, sandy } & 13 & 465 \\ \text { Sand } & 31 & 496 \\ \text { Shale } & 24 & 520 \\ \text { Sand } & 96 & 616 \\ \text { Shale } & 84 & 700 \\ \text { Shale, sandy } & 20 & 720 \\ \text { Shale } & 50 & 770 \\ \text { Sand } & 28 & 798 \\ \text { Shale } & 202 & 1,000 \\ \text { Shale, sandy } & 15 & 1,015 \\ \text { Shale } & 41 & 1,056 \\ \text { Shale, sandy and sand } & 15 & 1,071\end{array}$

Well TS-60-55-709

Owner: Montgomery County Precinct 4, Albert Sallas Park Driller: Lowe Water Wells, Inc.

\begin{tabular}{lcc}
\hline Description & $\begin{array}{c}\text { Thick- } \\
\text { ness } \\
\text { (feet) }\end{array}$ & $\begin{array}{c}\text { Depth } \\
\text { (feet) }\end{array}$ \\
\hline Clay & 52 & 52 \\
Sand & 41 & 93 \\
Clay & 17 & 110 \\
Sand & 42 & 152 \\
Clay & 58 & 210 \\
Sand & 66 & 276 \\
Clay & 24 & 300
\end{tabular}

Well Ts-60-61-307

Owner: Spring Creek U.D., Hell No. 2

Driller: Layne-Texas Co.

\begin{tabular}{lcc}
\hline \multicolumn{1}{c}{ Description } & $\begin{array}{c}\text { Thick- } \\
\text { ness } \\
\text { (feet) }\end{array}$ & $\begin{array}{c}\text { Depth } \\
\text { (feet) }\end{array}$ \\
\hline Fill dirt & 3 & 3 \\
Sand, gray and shale & 7 & 10 \\
Sand, red & 5 & 15 \\
Clay & 3 & 18 \\
Sand, white and gravel & 9 & 27 \\
Clay, gray & 13 & 40 \\
Clay and sand & 7 & 47 \\
Sand and clay & 35 & 82
\end{tabular}

Well TS-60-61-307--Cont inued

Sand 43

125

Sand and shale $\quad 55$

clay, red

211

clay, sandy and sand layers

Sand

44

255

Rock and I ime

272

Shale, sandy

274

Sand with shale streaks

Shale, sandy with sand streaks

295

Sand

310

Rock

Sand and rock streaks

Sand

Hard shale, sand and lime

17

2

13

8

15

310

13

323

1

324

6

330

Sand

$64 \quad 394$

Shale, hard

13

407

Sand

40

447

shale, sandy

453

6

534

Well Ts-60-63-109

Owner: Porter H.S.C.

Driller: $H$ and $H$ Water Well Drilling

\begin{tabular}{lcc}
\hline Description & $\begin{array}{c}\text { Thick- } \\
\text { ness } \\
\text { (feet) }\end{array}$ & $\begin{array}{c}\text { Depth } \\
\text { (feet) }\end{array}$ \\
\hline Clay & 60 & 60 \\
Sand & 20 & 80 \\
Clay & 20 & 100 \\
Sand & 20 & 120 \\
Clay & 30 & 150 \\
Sand & 30 & 180 \\
Clay & 10 & 190 \\
Sand & 50 & 240 \\
Clay & 70 & 310 \\
Sand & 70 & 380 \\
Clay & 20 & 400 \\
Sand & 40 & 440 \\
Clay & 134 & 574 \\
Sand & 26 & 600 \\
Clay & 48 & 648 \\
Sand & 20 & 668
\end{tabular}


Table 10.--Drillers' logs of wells in Montgomery County--Cont inued

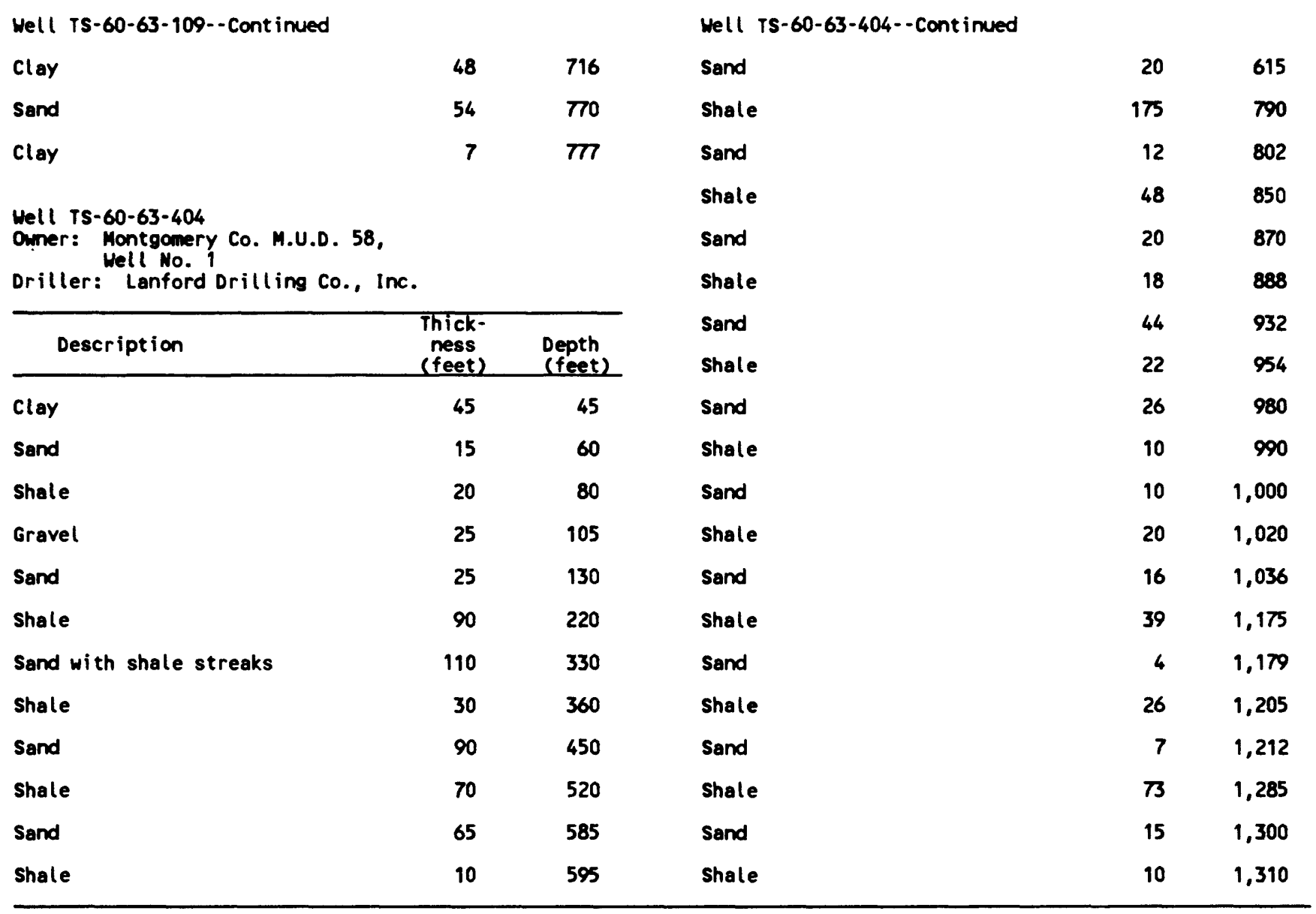


Table 11.- - Water levels in wells in Montgomery County

Owner : H.S.C., Water Supply Corporation; M.U.D., Municipal Utility District;

W.C.I.D., Water Control and Improvement District;

Altitude : Altitude of land surface above sea level

Screen : Top and botton of screened interval below land surface

Water level: Measured by the U.S. Geological Survey in hundredths of feet below land surface, except as noted

Well TS-60-35-202

Owner: Miss flower follett

Depth: 107 feet

Altitude: 327 feet

\begin{tabular}{cc}
\hline Date & $\begin{array}{l}\text { Water } \\
\text { level }\end{array}$ \\
\hline $08-18-86$ & 49.35 \\
$03-25-87$ & 49.80 \\
$01-25-88$ & 49.43 \\
$01-30-89$ & 49.72
\end{tabular}

Well TS-60-35-703

Owner: Dobbin-Plantersville W.S.C. Well No. 2

Screen: $697-760$ feet

Altitude: 290 feet

(Measurements reported by

the Texas Hater Development Board)

\begin{tabular}{cc}
\hline Date & $\begin{array}{c}\text { Water } \\
\text { level }\end{array}$ \\
\hline $03-13-87$ & 103.60 \\
$12-07-87$ & 109.60 \\
$02-21-89$ & 111.85
\end{tabular}

Well TS-60-37-712

Owner: San Jacinto Girl Scout Council, Camo Arnold

Screen: 500-521 feet

Al ti tude: 250 feet

(Measurements reported by the Texas Water Development Board)

\begin{tabular}{cc}
\hline Date & $\begin{array}{c}\text { Nater } \\
\text { level }\end{array}$ \\
\hline $03-12-87$ & 112.28 \\
$11-13-87$ & 123.90
\end{tabular}

Well is-60-37-713

Owner: San Jacinto Girl Scout Council. Camp Arnold

Screen: 505-520 feet

Alt itude: 250 feet

(Measurement reported by

the Texas Water Development Board)

\begin{tabular}{cc}
\hline Date & $\begin{array}{l}\text { Water } \\
\text { level }\end{array}$ \\
\hline $03-12-87$ & 113.47
\end{tabular}

Hell TS-60-43-511

Owner: Keenan W.S.C.

Screen: 342-389 feet

Altitude: 308 feet

(Measurements reported by

the Texas Hater Development Board)

\begin{tabular}{cc}
\hline Date & $\begin{array}{l}\text { Water } \\
\text { level }\end{array}$ \\
\hline $\begin{array}{ll}12-07-87 & 159.60 \\
02-22-89 & 162.72\end{array}$
\end{tabular}

Well Ts-60-44-315

Owner: Conroe Greenhouses

Screen: 400-415 feet

Alt itude: 260 feet

(Measurements reported by

the Texas Water Development Board)

\begin{tabular}{cc}
\hline Date & $\begin{array}{c}\text { Water } \\
\text { level }\end{array}$ \\
\hline $03-13-87$ & 111.87 \\
$11-13-87$ & 119.62
\end{tabular}

Well is-60-44-408

Owner: $\mathrm{Cl}$ iff Monk

Screen: 855-907 feet

Altitude: 255 feet

(Measurements reported by

the Texas Water Development Board)

\begin{tabular}{cc}
\hline Date & $\begin{array}{c}\text { Water } \\
\text { level }\end{array}$ \\
\hline $03-13-87$ & 107.85 \\
$12-16-87$ & 116.80 \\
$02-22-89$ & 119.00
\end{tabular}

Well TS-60-44-609

Owner: Wood

Depth: 800 feet

Altitude: 172 feet

(Measurements reported by San Jacinto River Authority)

\begin{tabular}{|c|c|}
\hline Date & $\begin{array}{l}\text { Water } \\
\text { level }\end{array}$ \\
\hline $\begin{array}{l}04-01-83 \\
09-30-83 \\
04-13-84 \\
10-03-84 \\
03-08-85\end{array}$ & $\begin{array}{l}11.68 \\
12.54 \\
12.14 \\
16.00 \\
12.34\end{array}$ \\
\hline $\begin{array}{l}10-23-85 \\
03-11-86 \\
10-09-86 \\
04-22-87 \\
10-15-87\end{array}$ & $\begin{array}{l}16.16 \\
12.93 \\
15.70 \\
12.12 \\
14.22\end{array}$ \\
\hline $\begin{array}{l}04-15-88 \\
10-25-88\end{array}$ & $\begin{array}{l}13.54 \\
14.55\end{array}$ \\
\hline
\end{tabular}

Well TS-60-45-207

Owner: City of Conroe, Well No. 13

Screen: $830-1,090$ feet Alt itude: 240 feet

(Measurements reported by the Texas Water Development Bosrd)

\begin{tabular}{cc}
\hline Date & $\begin{array}{l}\text { Water } \\
\text { level }\end{array}$ \\
\hline $03-09-87$ & $\begin{array}{l}140.05 \\
02-21-89\end{array}$ \\
178.65
\end{tabular}

Well TS-60-45-208

Owner: City of Conroe. Well No. 12

Screen: $840-1,135$ feet

Al titude: 225 feet

(Measurements reported by the Texas Water Development Board)

\begin{tabular}{cc}
\hline Date & $\begin{array}{c}\text { Water } \\
\text { level }\end{array}$ \\
\hline $03-09-87$ & 138.38 \\
$11-13-87$ & 156.95 \\
$02-21-89$ & 177.30
\end{tabular}

Well Ts-60-45-412

Owner: Harris-Galveston Coastal Subsidence District, Conroe Well No. 1

Screen: 241-261 feet Al t itude: 240 feet

\begin{tabular}{cc}
\hline Date & $\begin{array}{l}\text { Hater } \\
\text { level }\end{array}$ \\
\hline $10-25-89$ & 72.30 \\
$12-27-89$ & 82.24
\end{tabular}

Well TS-60-45-413

Owner: Harris-Galveston Coastal Subsidence District, Conroe Well No. 2

Screen: $99.5-109.5$ feet Altitude: 240 feet

\begin{tabular}{cc}
\hline Date & $\begin{array}{l}\text { Water } \\
\text { level }\end{array}$ \\
\hline $10-25-89$ & 52.10 \\
$12-27-89$ & 53.22
\end{tabular}


Table 11.--Water levels in wells in Montgomery County---Cont inued

Hell TS-60-45-414

Owner: Harris-Galveston Coastal Subsidence District, Conroe Well No. 3

Screen: $70-80$ feet

Altitude: 240 feet

\begin{tabular}{cc}
\hline Date & $\begin{array}{l}\text { Water } \\
\text { level }\end{array}$ \\
\hline $11-01-89$ & 54.80 \\
$12-27-89$ & 53.46
\end{tabular}

Well TS-60-45-503

Owner: City of Conroe, Well No. 4

Screen: $950-1,320$ feet

Alt itude: 212 feet

\begin{tabular}{cc}
\hline Date & $\begin{array}{l}\text { Water } \\
\text { level }\end{array}$ \\
\hline $01-17-89$ & 162.99
\end{tabular}

Well TS-60-45-504

Owner: City of Conroe, Hell No. 2

Screen: 1,099-1,221 feet Alt itude: 214 feet

\begin{tabular}{cc}
\hline Date & $\begin{array}{c}\text { Water } \\
\text { level }\end{array}$ \\
\hline $08-18-86$ & 151.02 \\
$03-25-87$ & 133.45 \\
$01-25-88$ & 158.84 \\
$01-17-89$ & 158.47
\end{tabular}

Well TS-60-45-507

Owner: City of Conroe, Well No.3

Screen: 1,050-1,238 feet Al ti tude: ' 205 feet

\begin{tabular}{cc}
\hline Date & $\begin{array}{c}\text { Hater } \\
\text { level }\end{array}$ \\
\hline $08-18-86$ & 131.83 \\
$03-25-87$ & 127.41 \\
$01-17-89$ & 158.30
\end{tabular}

Well TS-60-45-704

Owner: Boy Scouts of America, Camp strake

Screen: $1,000-1,160$ feet

Altitude: 133 feet

(Measurements reported by

San Jacinto River Authority)

\begin{tabular}{cc}
\hline Date & $\begin{array}{c}\text { Mater } \\
\text { level }\end{array}$ \\
\hline $04-01-83$ & 35.20 \\
$09-30-83$ & 45.44 \\
$04-12-84$ & 41.82 \\
$10-02-84$ & 46.78 \\
$03-05-85$ & 49.14 \\
& \\
$10-23-85$ & 59.98 \\
$03-11-86$ & 54.40 \\
$10-10-86$ & 60.82 \\
$04-23-87$ & 54.78 \\
$11-16-87$ & 61.74
\end{tabular}

Well TS-60-45-704--Cont.

$04-14-88 \quad 59.95$

10-25-88 $\quad 74.05$

Well TS-60-45-714

Owner: City of Conroe, Sewage Plant

Screen: 500-540 feet

Al ti tude: 120 feet

(Measurements reported by

the Texas Hater Development Boord)

\begin{tabular}{cc}
\hline Date & $\begin{array}{l}\text { Water } \\
\text { level }\end{array}$ \\
\hline $03-09-87$ & 100.20 \\
$11-13-87$ & 107.20 \\
$02-22-89$ & 119.10
\end{tabular}

Well TS-60-45-803

Owner: Brown Estate

Depth: 26 feet

Altitude: 178 feet

\begin{tabular}{cc}
\hline Date & $\begin{array}{l}\text { Water } \\
\text { level }\end{array}$ \\
\hline $08-18-86$ & 20.14 \\
$03-26-87$ & 15.12 \\
$01-25-88$ & 15.36 \\
$01-25-89$ & 20.30
\end{tabular}

Hell TS-60-45-809

Owner: East Plantation M.U.D. Well No. 2

Screen: $698-1,248$ feet

Altitude: 140 feet

(Measurements reported by

San Jacinto River Authority)

\begin{tabular}{cc}
\hline Date & $\begin{array}{c}\text { Water } \\
\text { level }\end{array}$ \\
\hline $09-23-83$ & 103.76 \\
$04-13-84$ & 117.62 \\
$10-02-84$ & 118.49 \\
$03-05-85$ & 112.40 \\
$03-11-86$ & 124.25 \\
& \\
$10-09-86$ & 117.67 \\
$04-22-87$ & 137.80 \\
$10-15-87$ & 140.68 \\
$10-25-88$ & 162.45
\end{tabular}

Hell TS-60-50-305

Owner: City of Magnolia, Hell No. 4

Screen: $572-622$

Altitude: 270 feet

(Measurements reported by the Texas Hater Development Boord)

\begin{tabular}{cc}
\hline Date & $\begin{array}{c}\text { Water } \\
\text { level }\end{array}$ \\
\hline $03-12-87$ & 192.90 \\
$12-16-87$ & 199.95 \\
$02-22-89$ & 204.45
\end{tabular}

Well TS-60-51-513

Owner: Nor thwest Water Systems, Hazy Hollow Well No. 1-A

Screen: 390-415 feet

Alt itude: 252 feet

(Measurement reported by

the Texas Hater Development Board)

\begin{tabular}{ll}
\hline Date & $\begin{array}{l}\text { Water } \\
\text { level }\end{array}$ \\
\hline $02-24-89$ & 133.75
\end{tabular}

Well TS-60-51-906

Owner: Klein Memorial Park

Screen: 249-274 feet

Altitude: 192 feet

(Measurements reported by the Texas Hater Development Board)

\begin{tabular}{cc}
\hline Date & $\begin{array}{l}\text { Water } \\
\text { level }\end{array}$ \\
\hline $03-12-87$ & 45.08 \\
$12-16-87$ & 46.20 \\
$02-22-89$ & 48.15
\end{tabular}

Hell TS-60-51-907

Owner: Pinehurst-Decker Prairie

Depth: 720 feet

Al ti tude: 189 feet

(Measurement reported by the Texas Water Development Board)

\begin{tabular}{cc}
\hline Date & $\begin{array}{l}\text { Water } \\
\text { level }\end{array}$ \\
\hline $02-24-89$ & 192.40
\end{tabular}

Well TS-60-53-206

Owner: River Plantation M.U.D., Well No. 2

Screen: 799-1,250 feet

Altitude: 115 feet

(Measurements reported by

San Jacinto River Authority)

\begin{tabular}{cc}
\hline Date & $\begin{array}{l}\text { Water } \\
\text { level }\end{array}$ \\
\hline $04-01-83$ & 40.68 \\
$04-13-84$ & 36.77 \\
$03-05-85$ & 52.05 \\
$10-23-85$ & 54.76 \\
$03-11-86$ & 50.17 \\
& \\
$10-09-86$ & 56.95 \\
$04-22-87$ & 52.80 \\
$11-12-87$ & 58.60 \\
$04-14-88$ & 55.25
\end{tabular}


Table 11.--Water levels in wells in Mantgomery County--Cont inued

Well TS-60-53-209

Owner: San Jacinto River Authority, Mongomery Co. M.U.D. 39

Screen: $660-880$ feet Alt i tude: 126 feet (Measurements reported by ouner)

\begin{tabular}{ll}
\hline Date & $\begin{array}{l}\text { Water } \\
\text { level }\end{array}$ \\
\hline $02-28-85$ & 152.92 \\
$10-21-85$ & 169.47 \\
$03-11-86$ & 155.35 \\
$10-08-86$ & 163.15 \\
$04-23-87$ & 172.04 \\
$11-13-87$ & 166.40 \\
$04-14-88$ & 161.20 \\
$10-27-88$ & 183.50 \\
$12-01-89$ & 185.00
\end{tabular}

Well TS-60-53-406

Owner: San Jacinto River Authority, Woodlands Well No. 5

Screen: $1,100-1,605$ feet Altitude: 155 feet

(Measurements reported by owner)

\begin{tabular}{ll}
\hline Date & $\begin{array}{c}\text { Water } \\
\text { level }\end{array}$ \\
\hline $09-23-83$ & 50.29 \\
$04-11-84$ & 48.76 \\
$10-01-84$ & 55.51 \\
$02-27-85$ & 51.40 \\
$10-22-85$ & 69.85 \\
$03-07-86$ & 54.13 \\
$09-17-86$ & 70.76 \\
$04-23-87$ & 62.95 \\
$10-21-87$ & 69.25 \\
$04-19-88$ & 67.35 \\
$10-27-88$ & 81.50
\end{tabular}

Well TS-60-53-514

Owner: City of Shenandoah, Hell No. 2

Screen: 725-970 feet

Altitude: 147

(Measurements reported by the Texas Water Development Board)

\begin{tabular}{cc}
\hline Date & $\begin{array}{l}\text { Water } \\
\text { level }\end{array}$ \\
\hline $03-11-87$ & 215.74 \\
$11-12-87$ & 219.45 \\
$02-22-89$ & 231.95
\end{tabular}

Hell TS-60-53-608

Owner: Indigo Corporation, Huntington Estates

Screen: $444-790$ feet

Altitude: 115 feet

(Measurements reported by

San Jacinto River Authority)

\begin{tabular}{cc}
\hline Date & $\begin{array}{c}\text { Water } \\
\text { level }\end{array}$ \\
\hline $10-02-84$ & 140.66 \\
$03-05-85$ & 137.62 \\
$10-21-85$ & 146.28 \\
$03-10-86$ & 146.47 \\
$10-08-86$ & 149.44 \\
$04-22-87$ & 145.94 \\
$11-12-87$ & 149.07 \\
$04-14-88$ & 143.02 \\
$10-25-88$ & 157.00
\end{tabular}

Hell TS-60-53-708

Owner: Montgomery Co. W.C.I.D. 1, Timberlakes Estates, Well No. 1

Screen: 794-1,170 feet

Altitude: 135 feet

(Measurements reported by

San Jacinto River Authority)

\begin{tabular}{cc}
\hline Date & $\begin{array}{c}\text { Hater } \\
\text { level }\end{array}$ \\
\hline $09-23-83$ & 198.77 \\
$04-11-84$ & 204.21 \\
$03-07-85$ & 216.38 \\
$10-23-85$ & 229.92 \\
$03-11-86$ & 227.01 \\
$10-15-86$ & 230.78 \\
$04-24-87$ & 246.33 \\
$10-27-87$ & 244.44 \\
$04-19-88$ & 230.35 \\
$06-24-88$ & 248.95 \\
$10-27-88$ & 261.10 \\
$09-27-89$ & 255
\end{tabular}

Well TS-60-53-709

Owner: San Jacinto River Authority, Montgomery CO. M.U.D. 6, Nell No. 1

Screen: 700-934 feet

Alt i tude: 130 feet

(Measurenents reported

by owner)

\begin{tabular}{ll}
\hline Date & $\begin{array}{l}\text { Water } \\
\text { level }\end{array}$ \\
\hline $03-28-83$ & 185.20 \\
$05-08-83$ & 196.76 \\
$05-09-83$ & 197.10 \\
$09-19-83$ & 205.06 \\
$04-11-84$ & 215.88 \\
$10-03-84$ & 241.99 \\
$02-27-85$ & 225.44 \\
$10-24-85$ & 245.30 \\
$03-12-86$ & 241.39 \\
$10-27-86$ & 243.10
\end{tabular}

Well TS-60-53-709--Cont.

$\begin{array}{ll}05-05-87 & 242.85 \\ 10-21-87 & 243.74 \\ 04-20-88 & 240.35 \\ 10-28-88 & 269.00\end{array}$

Well TS-60-53-712

Owner: San Jacinto River Authority, Montgomery Co. M.U.D. 6 , Hell No, 3

Screen: 1,168-1,538 feet

Altitude: 110 feet

(Measurements reported by owner)

\begin{tabular}{cc}
\hline Date & $\begin{array}{c}\text { Water } \\
\text { level }\end{array}$ \\
\hline $03-28-83$ & 27.89 \\
$09-19-83$ & 35.91 \\
$01-22-84$ & 21.66 \\
$01-23-84$ & 20.93 \\
$01-23-84$ & 20.65 \\
$04-13-84$ & 20.10 \\
$10-02-84$ & 52.07 \\
$02-27-85$ & 29.47 \\
$03-07-86$ & 36.75 \\
$10-15-86$ & 64.40 \\
$05-04-87$ & 69.80 \\
$10-21-87$ & 66.49 \\
$04-19-88$ & 72.35 \\
$10-27-88$ & 67.00
\end{tabular}

Hell TS-60-53-713

Owner: San Jacinto River Authority, Montgomery Co. M.U.D. 6 , Well No. 2

Screen: 1,150-1,690 feet

Al titude: 136 feet (Messurements reported by owner)

\begin{tabular}{cc}
\hline Date & $\begin{array}{l}\text { Water } \\
\text { level }\end{array}$ \\
\hline $03-28-83$ & 76.62 \\
$09-20-83$ & 64.86 \\
$01-21-84$ & 41.95 \\
$01-22-84$ & 36.17 \\
$01-23-84$ & 34.72 \\
$04-11-84$ & 44.98 \\
$10-01-84$ & 46.55 \\
$02-28-85$ & 42.09 \\
$10-22-85$ & 62.28 \\
$03-07-86$ & 42.49 \\
$10-27-86$ & 55.69 \\
$04-23-87$ & 49.52 \\
$10-22-87$ & 41.93 \\
$04-20-88$ & 63.85 \\
$10-26-88$ & 71.10
\end{tabular}


Table 11.-- Hater Levels in Hells in Montgomery County--Cont inued

Hell TS-60-53-714

Owner: San Jacinto River Authority, Montgomery Co. M.U.D. 6 , Well No. 4

Screen: $482-1,032$ feet

Al ti tude: 125 feet

(Measurements reported by owner)

\begin{tabular}{cc}
\hline Date & $\begin{array}{c}\text { Hater } \\
\text { level }\end{array}$ \\
\hline $05-08-83$ & 188.69 \\
$09-27-83$ & 191.92 \\
$04-11-84$ & 198.78 \\
$10-02-84$ & 226.96 \\
$03-05-85$ & 209.95 \\
$10-22-85$ & 222.00 \\
$03-12-86$ & 220.83 \\
$09-17-86$ & 230.08 \\
$05-04-87$ & 226.58 \\
$10-14-87$ & 233.55 \\
$04-19-88$ & 222.55 \\
$10-27-88$ & 257.30
\end{tabular}

Well TS-60-53-715

Owner: Montgomery Co. W.C.I.D. 1, Hell No. 2 Screen: $710-850$ feet

Altitude: 125 feet

(Measurements reported by

San Jacinto River Authority)

\begin{tabular}{cc}
\hline Date & $\begin{array}{c}\text { Water } \\
\text { level }\end{array}$ \\
\hline $04-08-83$ & 206.90 \\
$09-23-83$ & 203.62 \\
$04-12-84$ & 206.02 \\
$10-02-84$ & 234.23 \\
$03-07-85$ & 216.47 \\
$10-23-85$ & 237.19 \\
$03-11-86$ & 227.79 \\
$10-10-86$ & 245.27 \\
$04-24-87$ & 233.08 \\
$10-20-87$ & 237.09 \\
$04-19-88$ & 226.05 \\
$06-23-88$ & 246.15 \\
$10-27-88$ & 270.05
\end{tabular}

Well TS-60-53-821

Owner: Montgomery Co. M.U.D. 19. Nell No.

Screen: $620-1,012$ feet

Al ti tude: 125 feet

(Measurements reported by San Jacinto River Authority)

\begin{tabular}{cc}
\hline Date & $\begin{array}{c}\text { Water } \\
\text { level }\end{array}$ \\
\hline $03-28-83$ & 194.55 \\
$09-20-83$ & 203.25 \\
$04-11-84$ & 212.53 \\
$10-03-84$ & 241.73 \\
$03-06-85$ & 232.13
\end{tabular}

Well TS-60-53-821--Cont.

$\begin{array}{ll}10-21-85 & 258.30 \\ 03-10-86 & 223.11 \\ 10-14-86 & 261.20 \\ 04-23-87 & 266.33 \\ 11-12-87 & 246.39 \\ & \\ 04-15-88 & 256.90 \\ 10-25-88 & 265.70 \\ 10-14-89 & 287\end{array}$

Well TS-60-53-902

Owner: Montgomery Co. M.U.D. 19. Rayford Road

Screen: 291-415 feet

Altitude: 111 feet

(Measurements reported by

San Jacinto River Authority)

\begin{tabular}{cc}
\hline Date & $\begin{array}{c}\text { Hater } \\
\text { level }\end{array}$ \\
\hline $04-01-83$ & 101.00 \\
$09-26-83$ & 102.74 \\
$04-12-84$ & 100.61 \\
$10-03-84$ & 119.51 \\
$03-08-85$ & 104.87 \\
$10-21-85$ & 119.67 \\
$03-12-86$ & 110.44 \\
$10-08-86$ & 113.90 \\
$04-23-87$ & 112.13 \\
$11-12-87$ & 116.93 \\
$04-14-88$ & 111.00 \\
$10-25-88$ & 126.00
\end{tabular}

Well TS-60-54-306

Owner: Crystal Springs Water Co., thispering Pines, Hell Mo. 2

Screen: 200-218 feet

Altitude: 133 feet

(Measurements reported by the Texas Water Development Board)

\begin{tabular}{cc}
\hline Date & $\begin{array}{l}\text { Water } \\
\text { level }\end{array}$ \\
\hline $\begin{array}{l}11-12-87 \\
02-23-89\end{array}$ & $\begin{array}{l}54.10 \\
54.20\end{array}$
\end{tabular}

Well TS-60-54-610

Owner: Crystal Springs Water Co. Deer Glen, Hell No. 4

Screen: 217-237 feet

Altitude: 112 feet

(Measurements reported by

the Texas Hater Develop-

ment Bosrd)

\begin{tabular}{cc}
\hline Date & $\begin{array}{l}\text { Water } \\
\text { level }\end{array}$ \\
\hline $03-11-87$ & 37.50 \\
$11-12-87$ & 40.88 \\
$02-23-89$ & 42.40
\end{tabular}

Well TS-60-54-611

Owner: Crystal Springs Water Co., Deer Glen, Nell No. 5

Screen: $395-415$ feet

Altitude: 111 feet

(Measurements reported by the Texas Hater Development Board)

\begin{tabular}{cc}
\hline Date & $\begin{array}{l}\text { Water } \\
\text { level }\end{array}$ \\
\hline $03-11-87$ & 58.12 \\
$02-23-89$ & 50.22
\end{tabular}

Nell TS-60-54-804

Owner: Porter H.S.C. Hell No. 4

Screen: 400-550 feet

Al ti tude: 117 feet

(Measurements reported by the Texas Hater Development Boord)

\begin{tabular}{cc}
\hline Date & $\begin{array}{c}\text { Water } \\
\text { level }\end{array}$ \\
\hline $03-10-87$ & 106.77 \\
$11-12-87$ & 114.88 \\
$02-23-89$ & 112.05
\end{tabular}

Hell TS-60-55-313

Owner: Splendora H.S.C., Hell No. 3

Screen: $1,290-1,375$ feet Al ti tude: 120 feet

(Measurements reported by the Texas Water Development Board)

\begin{tabular}{cc}
\hline Date & $\begin{array}{l}\text { Water } \\
\text { level }\end{array}$ \\
\hline $03-10-87$ & 20.20 \\
$11-12-87$ & 18.70 \\
$02-23-89$ & 27.60
\end{tabular}

Well TS-60-55-314

Owner: Splendora W.S.C., Well No. 4

Screen: 290-395 feet Altitude: 120 feet (Measurement reported by the Texas Water Development Board)

\begin{tabular}{cc}
\hline Date & $\begin{array}{l}\text { Hater } \\
\text { level }\end{array}$ \\
\hline $02-23-89$ & 62.80
\end{tabular}

Well TS-60-62-604

Owner: Montgomery Co., M.U.D. 48, Kingwood Place, Well Mo. 1

Screen: $1,164-1,450$ feet

Altitude: 125 feet (Measurements reported by the Texas Water Development Board)

\begin{tabular}{cc}
\hline Date & $\begin{array}{l}\text { Water } \\
\text { level }\end{array}$ \\
\hline $\begin{array}{ll}11-12-87 & 171.05 \\
02-23-89 & 176.00\end{array}$
\end{tabular}




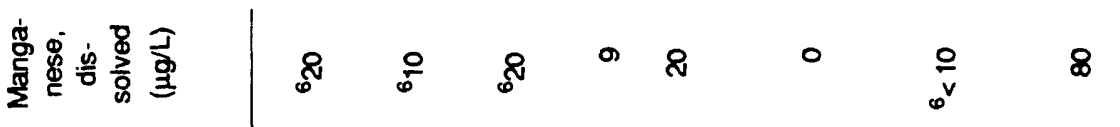

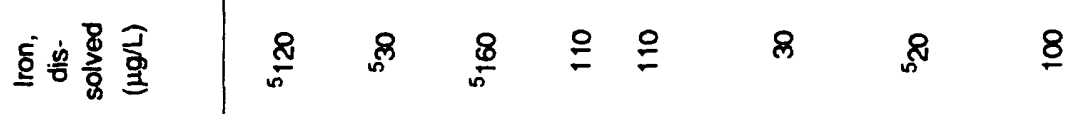

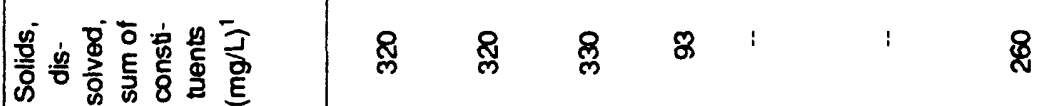

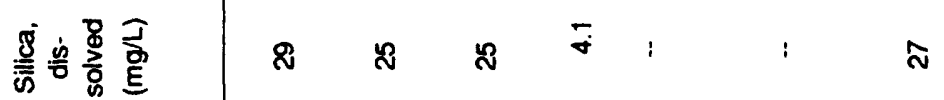

总是要

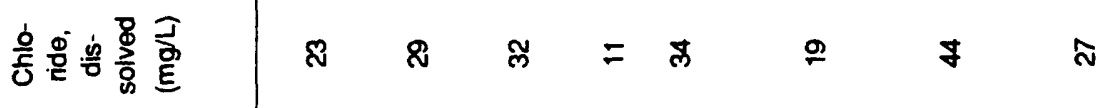

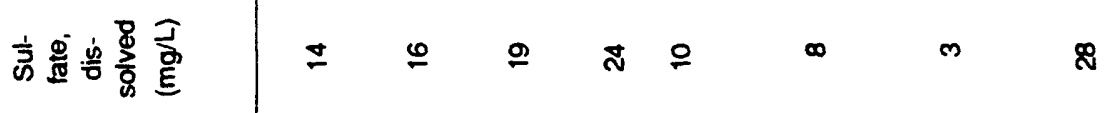

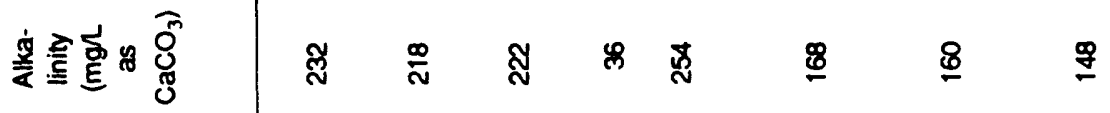

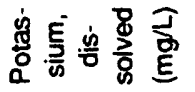

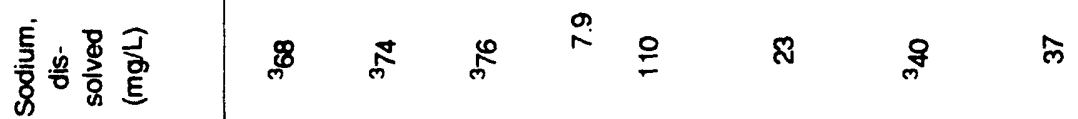

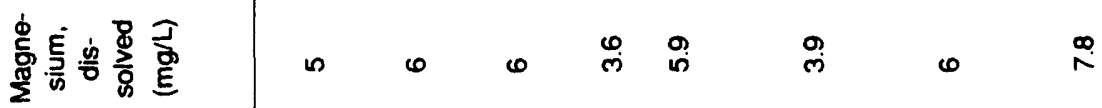

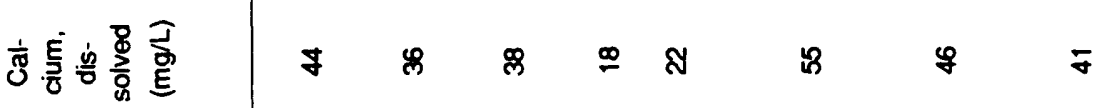

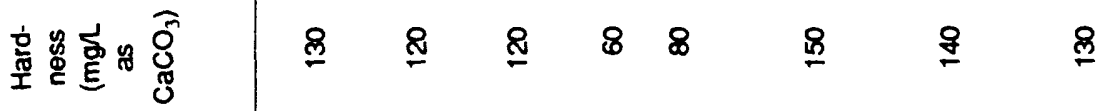

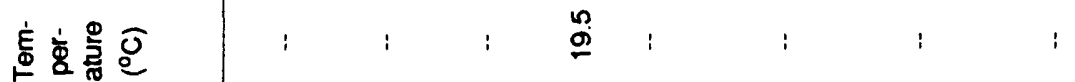

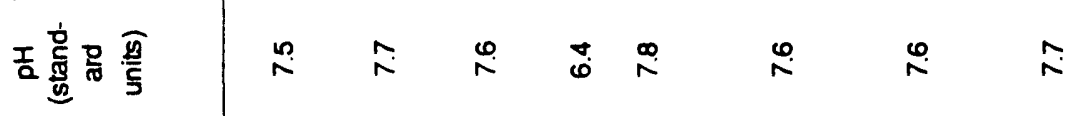

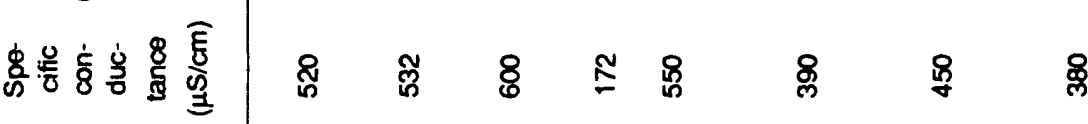

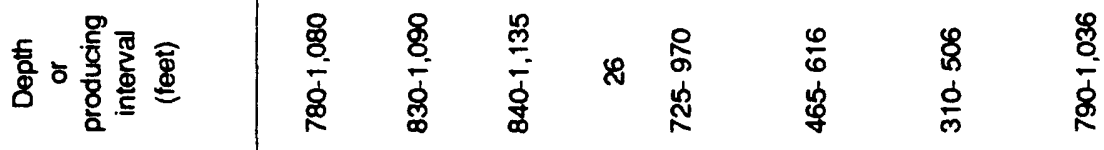

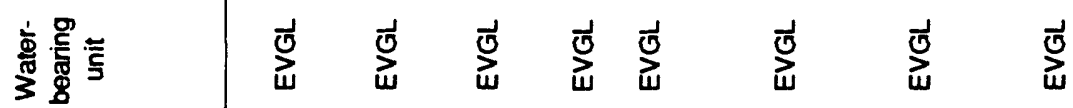

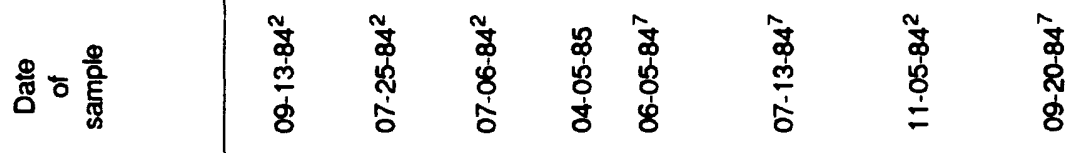

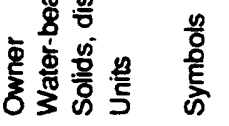

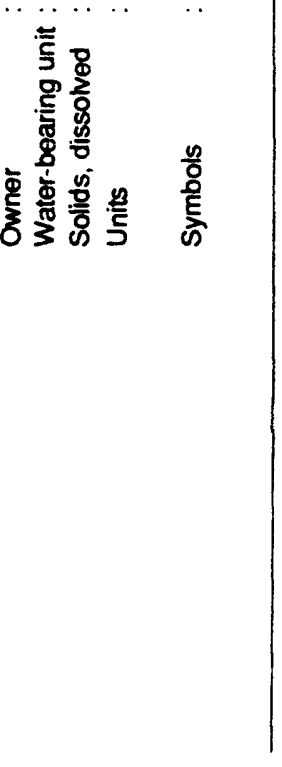

*L.ร. GOVIRNMENT PRINTING OFFICE: 1992-661-490 45 